\title{
Una mirada en el tiempo: mejoramiento genético de café mediante la aplicación de la biotecnología ${ }^{1}$
}

\section{A look back in time: genetic improvement of coffee through the application of biotechnology}

\author{
Jimmy Villalta-Villalobos ${ }^{2}$, Andrés Gatica-Arias²
}

1 Recibido: 7 de agosto, 2018. Aceptado: 18 de octubre, 2018. Este trabajo formó parte del Proyecto 111-B3-206 de la Universidad de Costa Rica, titulado "Establecimiento de protocolos para el mejoramiento genético de variedades costarricenses de café (Coffea arabica L.) con el fin ulterior de conferir resistencia a enfermedades y plagas". Además este trabajo se logró con la ayuda del fondo de apoyo a tesis de posgrado otorgado por la Vicerrectoría de Investigación y el Sistema de Estudios de Posgrado de la Universidad de Costa Rica. San José, Costa Rica.

2 Universidad de Costa Rica, Escuela de Biología, Laboratorio Biotecnología de Plantas. San José, San Pedro de Montes de Oca, Costa Rica. j10villalta@gmail.com (https://orcid.org/0000-0001-5235-4917), andres.gatica@ucr.ac.cr (https://orcid.org/0000-0002-3841-0238).

\section{Resumen}

Introducción. El café (Coffea spp) es uno de los cultivos más importantes a nivel mundial y provee sustento económico a millones de personas en países en vías de desarrollo. Existen más de las 130 especies del género Coffea, pero solo tres son cultivadas comercialmente: Coffea arabica $\mathrm{L}$. $(2 \mathrm{n}=4 \mathrm{x}=44)$, Coffea canephora $\mathrm{P} .(2 \mathrm{n}=2 \mathrm{x}=22)$ y Coffea liberica Bull. $(2 \mathrm{n}=2 \mathrm{x}=22)$. Las cuales presentan limitantes para su mejoramiento genético a través de programas convencionales por su carácter perenne y diferencias de nivel de ploidía e incompatibilidad. Además, existen características de importancia como resistencia a plagas o patógenos, que no se encuentran presentes en el germoplasma disponible. Técnicas de ingeniería genética se han utilizado para solventar esta barrera y se han generado avances significativos durante las últimas décadas. Objetivo. El objetivo del presente trabajo fue proporcionar un panorama de las metodologías y avances en mejoramiento genético a través del tiempo que se han realizado en café, y finaliza con perspectivas sobre el uso de nuevas tecnologías que han surgido en los últimos años. Desarrollo. El mejoramiento inició con la selección por cruces y retrocruces interespecíficos, para pasar a la selección asistida por marcadores moleculares. Posteriormente, el cultivo y fusión de protoplastos fue reportado, con el inconveniente en su proceso de regeneración. La ingeniería genética por medio de las técnicas físicas (electroporación y biobalística) y biológicas (A. tumefaciens y A. rhizogenes), ayudó a sobrepasar las limitantes de regeneración, aunque los procesos de optimización aún son laboriosos, por lo que, nuevas tecnologías de edición de genomas como CRISPR-Cas9, pueden solucionar problemas de tiempo y trabajo en el laboratorio para el cultivo. Conclusión. El mejoramiento del café inició hace tres décadas y ha progresado principalmente desde el inicio de las tecnologías transgénicas, y con las nuevas técnicas de modificación específica de genes, el cultivo se beneficiará en los próximos años.

Palabras clave: protoplastos, electroporación, ingeniería genética, Agrobacterium tumefaciens, plásmido. 


\begin{abstract}
Introduction. Coffee (Coffea spp) is one of the most important crops worldwide, providing economic livelihood to millions of people in developing countries. There are more than 130 species of the Coffea genus, but only three species are commercially cultivated: Coffea arabica $\mathrm{L}$. $(2 \mathrm{n}=4 \mathrm{x}=44)$, Coffea canephora $\mathrm{P}$. $(2 \mathrm{n}=2 \mathrm{x}=22)$, and Coffea liberica $\mathrm{L} . \quad(2 \mathrm{n}=2 \mathrm{x}=22)$. Which present limitations for their genetic improvement through conventional programs because of their perennial nature and differences in level of ploidy and incompatibility. Additionally, there are important characteristics such as resistance to pests or pathogens, which are not present in the available germplasm. Genetic engineering techniques have been used to solve this barrier, and significant advances have been generated during the last decades. Objective. The objective of this work was to provide an overview of the methodologies and advances in coffee genetic improvement through time, and ends with perspectives about the use of new technologies that have emerged in recent years. Development. The improvement began with the selection by crosses and interspecific backcrosses, to move to the selection assisted by molecular markers. Subsequently, the culture and fusion of protoplasts was reported, with the disadvantage in the regeneration process. Genetic engineering through physical (electroporation and biolistics), and biological techniques (A.tumefaciens and A.rhizogenes) helped to overcome the limitations of regeneration, although the optimization processes are still laborious, so, new technologies for editing genomes such as CRISPR-Cas9, can solve problems of time and work in the laboratory for the crop. Conclusion. The improvement of coffee began three decades ago and has progressed mainly since the beginning of transgenic technologies, and with the new techniques of specific modification of genes, the crop will benefit in the coming years.
\end{abstract}

Keywords: protoplasts, electroporation, genetic engineering, Agrobacterium tumefaciens, plasmid.

\title{
Introducción
}

El café (Coffea spp.) es un cultivo de suma relevancia a nivel mundial por su alto valor como bebida de consumo (Alemayehu, 2017) y por ser uno de los productos agrícolas más importantes, ocupando el segundo puesto en el comercio internacional luego del petróleo (Labouisse et al., 2008). Las regiones tropicales y subtropicales del mundo son los lugares donde se cultiva mayormente, derivándose, directa o indirectamente de su producción, los ingresos de más de 125 millones de personas (Tran et al., 2016).

El género Coffea L., comprende más de 130 especies, de las cuales las más cultivadas comercialmente son C. arabica L., C. canephora P. y C. liberica Bull. (Fernández et al., 2010). Coffea arabica L. es la especie más importante y la preferida en el mercado, teniendo una participación promedio entre las cosechas 2014-2015 y 20152016 de 58,1\% en la producción mundial (ICAFE, 2016).

Todas las especies de café, a excepción de Coffea arabica L., Coffea heterocalyx L. y Coffea anthonyi L., son autoincompatibles (Davis et al., 2006), y además C. arabica L. es la única especie no diploide (Mishra y Slater, 2012). La especie arabica es un alotetraploide autofértil $(2 n=4 x=44)$, producto de la hibridación espontánea entre Coffea canephora Pierre. (progenitor paterno) y Coffea eugenoides L. (progenitor materno) (Lashermes et al., 1999), con un tamaño de genoma de $1300 \mathrm{Mpb}$ (Lashermes et al., 2008).

Las diferentes ploidías en el género Coffea obstaculizan la introducción de características agronómicas de las especies diploides hacia las tetraploides y por esto, es tan importante el uso de técnicas que puedan romper estas barreras entre especies y que sirvan para complementar los programas tradicionales de mejoramiento genético y, a la vez la base genética disponible. El mejoramiento del café y la obtención de un nuevo cultivar con base en las metodologías tradicionales, es un proceso que requiere alrededor de treinta años (Melese, 2016) y esfuerzos, ya que comprende varios pasos como la selección de las especies o variedades a utilizar, su consiguiente hibridación y evaluación de la progenie resultante, en algunos casos retrocruces, y cruces interespecíficos (Orozco y Schieder, 1982). 
El objetivo del presente trabajo fue proporcionar un panorama de las metodologías y avances en mejoramiento genético a través del tiempo que se han realizado en café, y finaliza con perspectivas sobre el uso de nuevas tecnologías que han surgido en los últimos años.

\section{Mejoramiento genético convencional}

En el caso de $C$. arabica L., los esfuerzos de mejoramiento genético convencional se han enfocado a la hibridación, selección genealógica y selección por cruces y retrocruces interespecíficos, con el fin de transferir factores de resistencia a patógenos y plagas, mejorar la adaptación y el rendimiento del cultivo. Además, en el mejoramiento genético convencional de café, se ha utilizado la introducción y selección de plantas, cruces artificiales con parentales seleccionados y ensayos de mutagénesis y radiación en semillas (Berthouly, 1997; Solano, 2001).

El híbrido Timor (C. arabica L. x C. canephora), ha sido ampliamente utilizado por su resistencia a Hemileia vastatrix, derivada de cuatro genes mayores de resistencia de $C$. canephora. De esta manera, el cruce entre el híbrido Timor y el mutante natural Caturra Rojo dio origen a la variedad Catimor, la cual presenta resistencia a la roya. Por otro lado, con el fin de conferirle vigor a la variedad Catimor, se llevó a cabo un retrocruce entre Catimor y la variedad Catuaí. Además, con el fin de obtener variedades resistentes a la roya, la antracnosis de los frutos y a los nematodos, en Brasil se desarrolló la variedad Icatu, la cual es producto del cruzamiento artificial entre $C$. arabica tetraploide y C. canephora tetraploide (Berthouly, 1997). En 1985 en Kenia, se liberó el híbrido Ruiri 11, el cual presenta resistencia a la roya, la antracnosis del fruto, así como alta producción y calidad (Agwanda, 1999).

Desde 1991 en Centroamérica se desarrolla un programa de mejoramiento genético convencional de café, en el cual participan varias instituciones tales como PROMECAFE, los institutos de café de los países centroamericanos, instituciones nacionales de investigación en café, la cooperación francesa (CIRAD, ORSTOM, MAE) y el Centro Agronómico Tropical de Investigación y Enseñanza (CATIE). Dicho programa tiene como finalidad cruzar variedades tradicionales de América Latina con individuos silvestres de Etiopía y Sudán, para recuperar una fuente de variabilidad y, posteriormente propagar a gran escala los híbridos F1 de C. arabica obtenidos. La importancia de propagar dichos híbridos se basa en las características de resistencia a la roya, tolerancia a nematodos, gran vigor y alta productividad (Albarrán, 1999). Sin embargo, la incorporación de genes que confieran características específicas de interés agronómico al genoma de las variedades comerciales de café, mediante mejoramiento genético convencional, es un proceso largo y difícil de lograr, debido al prolongado ciclo de vida de las especies perennes, la heterogeneidad y al extenso período de evaluación requerido (Carneiro, 1993).

Una revisión detallada del papel de los objetivos del mejoramiento genético en el café se puede consultar en Van-Der-Vossen et al. (2015).

\section{Mejoramiento genético asistido por marcadores moleculares}

Entre los principales marcadores moleculares utilizados en cultivares de importancia comercial están las aloenzimas, RFLP (Restriction Fragment Length Polymorphic), RAPD (Random Amplified Polymorphic DNA), AFLP (Amplified Fragment Length Polymorphism), SNP (Single Nucleotide Polymorphism) y microsatélites SSR (Simple Sequence Repeats) (Azofeifa, 2006). Los marcadores moleculares se han utilizado en café para evaluar la diversidad genética de las especies y construir mapas genéticos (De-Kochko et al., 2010); además, para la evaluación de introgresión, determinación del modo de herencia de enfermedad y resistencia a plagas, evaluación de calidad de bebida y análisis e identificación de loci de rasgos cuantitativos (QTL), los cuales tienen implicaciones de gran importancia para el mejoramiento genético (Melese, 2016). 
El desarrollo de la selección asistida por marcadores (MAS) proporciona una alternativa para el mejoramiento genético convencional de café (Lashermes et al., 2000). El principio general de MAS es el uso y la selección de un marcador molecular identificado vinculado a un gen para un rasgo específico, en lugar de la selección del rasgo mismo, y así reducir el número de retrocruzamientos requeridos (Lashermes et al., 2000). Así por ejemplo, Gichuru et al. (2008) identificaron ocho AFLP y dos marcadores de microsatélites, que se asignaron a un único fragmento cromosómico introgresado de C. canephora, en fenotipos de café resistentes a la enfermedad causada por Colletotrichum kahawae. Por otro lado, Agwanda et al. (1997) identificaron tres marcadores de RAPD asociados estrechamente con la resistencia a la enfermedad de la baya de café.

Una revisión detallada del papel de varios marcadores moleculares en el café se puede consultar en la literatura (Hendre y Aggarwal, 2007) y, por lo tanto, fuera del alcance de la presente revisión.

\section{La necesidad del mejoramiento genético no convencional en café}

Desde su aplicación en plantas hace más de veinticinco años, la transformación genética se ha convertido en una herramienta indispensable en el mejoramiento genético de cultivos (De-Block et al., 1984). La tecnología de transformación genética es considerada como una extensión de las tecnologías convencionales de mejoramiento genético (Zhong, 2001), y ofrece oportunidades únicas para superar barreras de compatibilidad entre especies, y así desarrollar fenotipos con rasgos deseados que no están disponibles en el germoplasma de las plantas de cultivo (Mishra y Slater, 2012). Los principales objetivos del mejoramiento genético no convencional a través del uso de la técnica de ingeniería genética en el café son introducir nuevos rasgos en genotipos de élite, desarrollar nuevos cultivares con características deseables como resistencia a plagas y a enfermedades, resistencia a herbicidas, tolerancia a sequía y heladas, y mejorar la calidad de la taza (Mishra y Slater, 2012).

La transformación genética de café tiene dos aplicaciones principales: (1) una herramienta para la validación de la función del gen y (2) la producción de cultivos transgénicos con características agronómicamente importantes (Mishra y Slater, 2012). Además, tecnologías como los marcadores moleculares, la multiplicación in vitro, la genómica, la proteómica y la metabolómica, deberían complementar los esfuerzos de mejoramiento convencional para acelerar el mejoramiento genético del café (Mishra y Slater, 2012).

\section{Cultivo y fusión de protoplastos}

La hibridación somática o fusión de protoplastos es una técnica biotecnológica para el mejoramiento genético de cultivos vegetales. Su uso se basa en el aislamiento y unión de dos células somáticas que carecen de pared celular (protoplastos), para formar una única célula híbrida que tiene el potencial de regenerar y desarrollar una planta completa usando técnicas de cultivo in vitro (Pensabene, 2009).

Para desproveer a la célula de su pared celular y obtener los protoplastos (citoplasma y núcleo rodeados por una membrana plasmática), se utilizan tres vías: i) digestión enzimática con pectinasas, celulasas, hemicelulasas individualmente o en combinación, ii) disrupción mecánica con las fuerzas de corte (sonicadores, homogenizadores de alta presión y molinos de perlas) que deforman las células hasta el rompimiento de sus cubiertas, y iii) combinación de las vías anteriores (Gutiérrez et al., 2003).

Con el empleo de químicos como polietilenglicol (PEG) o procedimientos que involucran una fuente eléctrica, los protoplastos de diversas plantas donadoras pueden fusionarse y generar híbridos somáticos, que luego pueden regenerar en plantas y generar nuevos genotipos como resultado de la combinación de especies incompatibles sexualmente (Espejo et al., 2008). En la fusión se da la coexistencia de dos núcleos y de los citoplasmas de 
ambos protoplastos, lo cual genera una etapa de heterocariosis. Si se da la fusión de núcleos durante la mitosis, la producción de las células híbridas se completa (Montero y Jimenéz, 2009). En café existen pocos casos en los que esta técnica se ha implementado con propósitos de estandarización del método para posteriores usos en mejoramiento genético.

En 1980, se aislaron protoplastos a partir de callos embriogénicos de sesenta días de edad, provenientes de segmentos de hoja de $C$. arabica L. Bourbon, y se logró la regeneración de la pared celular y la proliferación de callo embriogénico en un $30 \%$ de los casos (Sondahl et al., 1980). Hojas de vitroplantas de C. arabica L. y C. canephora Pierre, se emplearon para aislar protoplastos, por medio de una disrupción enzimática al incubar los explantes por cuatro horas en una solución de celulasa R10 (3\%), pectoliasa Y23 (0,5 \%) y manitol (0,6 M), a un pH de 5,8. Los protoplastos aislados se cultivaron a $25{ }^{\circ} \mathrm{C}$ en oscuridad, donde proliferaron y formaron callos embriogénicos, los cuales posteriormente murieron sin su conversión en embriones somáticos (Orozco y Schieder, 1982).

En 1987 se aislaron protoplastos a partir de embriones somáticos derivados de suspensiones celulares de $C$. canephora L. (Schopke et al., 1987). Los protoplastos se colocaron en un medio suplementado con 0,5 mg..$^{-1}$ de Kinetina, 0,5 mg. $1^{-1}$ de ácido naftalenacético (ANA) y $0,5 \mathrm{mg} .1^{-1}$ de 2,4-diclorofenoxiacético (2,4-D). Luego de varios subcultivos, obtuvieron la formación de callo embriogénico, el cual colocaron en un medio de cultivo sin reguladores de crecimiento para su posterior desarrollo a embriones somáticos en etapa globular y, finalmente a plantas que se transfirieron al invernadero.

A inicios de los noventa, se regeneraron plantas a partir de protoplastos aislados de suspensiones celulares de C. arabica L. y C. canephora. Los protoplastos se obtuvieron por digestión enzimática (con celulasa, macerozima y pectoliasa), para luego colocarlos en medio Blaydes modificado con 2,4-D y ANA. Luego de siete meses, los callos embriogénicos resultantes se colocaron en medio semisólido de germinación de embriones somáticos, y las plantas obtenidas se aclimataron en el invernadero (Spiral y Petiard, 1991). En el mismo año, se lograron regenerar plantas a partir de protoplastos aislados de suspensiones celulares de $C$. arabica L. var. Caturra, donde los rendimientos de viabilidad de los protoplastos fueron de $1 \times 10^{5}-6 \times 10^{5}$ protoplastos. $\mathrm{g}^{-1}$ en peso fresco. Los callos embriogénicos obtenidos en el medio de cultivo suplementado con 0,5 mg..$^{-1}$ de bencilaminopurina (BAP), 0,5 mg..$^{-1}$ de 2,4-D y $0,5 \mathrm{mg} . \mathrm{l}^{-1}$ de ANA, se subcultivaron en un medio sin reguladores de crecimiento para obtener los embriones somáticos, de los cuales, el $70 \%$ se desarrollaron en plantas que se llevaron hasta etapa de invernadero (Acuña y De-Peña, 1991).

En 1994 se reportaron rendimientos en la regeneración y viabilidad de protoplastos de C. arabica L. de $3,5 \times 10^{6}-4,6 \times 10^{6}$ protoplastos. $\mathrm{g}^{-1}$ en peso fresco, lo que equivale de 10 a 15 veces los obtenidos por Acuña y DePeña (1991). Dichos rendimientos se lograron al utilizar $6 \mathrm{~g}$ de peso fresco de suspensiones celulares, las cuales se plasmolizaron en $100 \mathrm{ml}$ de sales $\mathrm{K} 3$ suplementadas con $0,5 \mathrm{M}$ de sacarosa por $60 \mathrm{~min}$ a $24{ }^{\circ} \mathrm{C}$, para luego tomar 1 g de las células plasmolizadas en una solución enzimática que consistió de macerozima R10 (0,8 \%), celulasa R10 $(1 \%)$ y driselasa $(0,5 \%)$, para finalmente colectarlas y purificarlas (Grézes et al., 1994). La principal razón que obstaculiza el uso amplio de esta técnica fue que presentó muchos problemas en la etapa de regeneración (Barros et al., 2000).

\section{Ingeniería genética}

La ingeniería genética de plantas ha revolucionado las técnicas de mejoramiento genético convencionales, ya que a pesar de tener los mismos objetivos (identificación, selección, incorporación y herencia de rasgos a la siguiente generación), posee las grandes ventajas de aumentar el rango de caracteres de interés a transferir a las especies que pueden ser de origen vegetal, animal o microbiano, y de modificar puntualmente a los organismos al integrar uno o pocos genes, y no el genoma completo (De-Gluglielmo, 2009). 
En café, la ingeniería genética se ha enfocado en dos objetivos: i) elucidar la función, regulación e interacción de genes agronómicos importantes e ii) introducir nuevos rasgos en genotipos élite, desarrollar nuevos cultivares con rasgos deseables como resistencia a plagas, patógenos y herbicidas, tolerancia a sequía y heladas, y mejoramiento de la calidad de tasa (Fernández et al., 2010).

Se han utilizado tanto los métodos biológicos con el empleo de bacterias del género Agrobacterium, como los físicos en los que se encuentran la electroporación y biobalística (Gatica et al., 2009), los cuales se analizarán a continuación.

\section{Métodos físicos directos de introducción de genes de interés en el genoma}

\section{Electroporación}

La técnica de electroporación se basa en la permeabilización de las membranas celulares al aumentar la conductividad eléctrica. Esto ocasiona que las membranas se desestabilicen y generen poros momentáneos y reversibles, por los cuales ocurre la absorción por parte de las células del ácido desoxirribonucleico (ADN) foráneo que contiene el o los genes de interés (Díaz y Chaparro, 2012). Además de la inserción de ácidos nucleicos, se pueden ingresar drogas, colorantes o proteínas a las células (Mishra y Slater, 2012).

En café la electroporación se utilizó inicialmente por Barton et al. (1991) (Cuadro 1), quienes electroporaron protoplastos de $C$. arabica L. con los genes nptII y gus, bajo el control del promotor pGA472, y lograron regenerar los embriones somáticos y las plantas resistentes a kanamicina; sin embargo, por su débil desarrollo radical las plantas no sobrevivieron. Tres años después, Van-Boxtel (1994) logró la inserción del gen gus en protoplastos aislados de suspensiones celulares no embriogénicas, pero solo obtuvo una expresión transitoria del transgen, con una actividad máxima de expresión a los 6-9 días luego de realizada la electroporación, al aplicar un campo de fuerza de $150 \mathrm{~V} \cdot \mathrm{cm}^{-1}$, lo cual a su vez aumentó la viabilidad de los protoplastos.

Embriones somáticos en etapa torpedo se pretrataron por una hora con una solución enzimática ( $2 \%$ de celulasa y $1 \%$ de macerozima en buffer $5 \mathrm{mM}$ MES, $0,5 \mathrm{M}$ de Manitol y $25 \mathrm{mM} \mathrm{CaCl}_{2}, \mathrm{pH} 5,8$ ), para posteriormente introducirles el plásmido pCAMBIA3201 (gus y bar) bajo el control del promotor duplicado CAMV35S, mediante electroporación a $375 \mathrm{~V}$ y $900 \mu \mathrm{F}$ (Fernández y Menéndez, 2003). El estudio mostró una regeneración máxima a través de embriogénesis somática secundaria, y se observaron los puntos de color azulado de un resultado positivo de expresión transitoria con la prueba histoquímica del gen gus; además, se obtuvieron las amplificaciones respectivas para ambos transgenes mediante la técnica de reacción en cadena de la polimerasa (PCR, por sus siglas en inglés) (Fernandez y Menéndez, 2003).

Las N-metiltransferasas (NMT) se encuentran directamente relacionadas con la formación de la cafeína a partir de la xantosina (Denoeud et al., 2014) y, por ello, en el 2007 se realizaron ensayos de electroporación en endospermos de C. canephora L. con el plásmido pCAMBIA1301 (gen gus controlado por un promotor de la NMT), con el fin de localizar donde ocurre la expresión de estas enzimas. Se logró demostrar que el promotor utilizado podía controlar la expresión de genes reporteros en endospermos de café al observarse la coloración azulada característica de una prueba gus positiva, y se concluyó que la expresión transitoria del transgen estaba dirigida hacia la superficie externa de las vacuolas, lo cual confirmaron con el empleo de anticuerpos específicos para NMT (Kumar et al., 2007).

En el 2011, suspensiones celulares de C. arabica L. cv. Caturra rojo se electroporaron con el plásmido pDBGUS-INT (gus y bar) bajo el control del promotor CAMV35S, con el objetivo de determinar el efecto de la capacitancia y fuerza de campo sobre la vitalidad de las células, 24, 48 y 72 h posteriores a su aplicación, y para determinar la influencia del buffer de electroporación utilizado sobre la expresión transitoria del transgen gus (Barbón et al., 2011). Al utilizar el buffer A (10 mM de N-2-hidroxyethyl piperazine-N-2ethanesulfonic (HEPES), 
Cuadro 1. Resumen de estudios de electroporación y biobalística en café (1991-2011).

Table 1. Summary of electroporation and biobalistic studies in coffee (1991-2011).

\begin{tabular}{|c|c|c|c|c|c|c|c|c|}
\hline \multirow[b]{2}{*}{ Año } & \multicolumn{8}{|c|}{ Electroporación } \\
\hline & Coffea & Explante & Vector & Promotor & Gen selec. & Gen interés & Resultados & Referencia \\
\hline 1991 & arabica & $\mathrm{P}$ & NR & pGA472 & $n p t I I$ & gus & $\begin{array}{l}\text { Integración de } n p t I I, \text { No } \\
\text { regeneración }\end{array}$ & $\begin{array}{c}\text { Barton et al., } \\
1991\end{array}$ \\
\hline 1994 & arabica & $\mathrm{P}$ & NR & $\mathrm{EF} 1 \alpha-\mathrm{A} 1$ & NR & gus & $\begin{array}{l}\text { Expresión gus } \\
\text { transitoria }\end{array}$ & Van-Boxtel, 1994 \\
\hline 2003 & arabica & ES torpedo & pCAMBIA3201 & CaMV35S & bar & gus & $\begin{array}{c}\text { Expresión gus y } \\
\text { formación de embriones } \\
\text { secundarios }\end{array}$ & $\begin{array}{c}\text { Fernandez y } \\
\text { Menéndez, } 2003\end{array}$ \\
\hline 2007 & canephora & Endospermo & pCAMBIA1301 & CaMV35S & $h p t$ & gus & $\begin{array}{c}\text { Expresión gus } \\
\text { transitoria }\end{array}$ & $\begin{array}{c}\text { Kumar et al., } \\
2007\end{array}$ \\
\hline \multirow[t]{2}{*}{2011} & arabica & $\mathrm{SC}$ & pDB-GUS-INT & CaMV35S & bar & gus & $\begin{array}{l}\text { Expresión } g u s \\
\text { transitoria }\end{array}$ & $\begin{array}{c}\text { Barbón et al., } \\
2011 \\
\end{array}$ \\
\hline & \multicolumn{8}{|c|}{ Biobalística } \\
\hline Año & Coffea & Explante & Vector & Promotor & Gen selec. & Gen interés & Resultados & Referencia \\
\hline 1995 & arabica & SH & pPIGK & $\mathrm{EF} 1 \alpha-\mathrm{A} 1$ & bar & gus & $\begin{array}{l}\text { Expresión gus } \\
\text { transitoria }\end{array}$ & $\begin{array}{c}\text { Van-Boxtel et al., } \\
1995\end{array}$ \\
\hline 2000 & arabica & $\mathrm{EC}$ & $\begin{array}{l}\mathrm{pB} 1426 \\
\mathrm{pAG} 1 \\
\mathrm{pAA} 4\end{array}$ & NR & $\begin{array}{c}--- \\
\text { ahas } \\
----\end{array}$ & $\begin{array}{c}\text { gus } \\
\text { gus } \\
\alpha-\mathrm{AI} 1\end{array}$ & $\begin{array}{l}\text { Expresión gus } \\
\text { transitoria }\end{array}$ & Barros et al., 2000 \\
\hline 2001 & $\begin{array}{l}\text { arabica } \\
\text { canephora }\end{array}$ & CE y EC & NR & NR & NR & gus & $\begin{array}{l}\text { Expresión gus } \\
\text { transitoria }\end{array}$ & Barros et al., 2001 \\
\hline 2002 & arabica & $\mathrm{CE}$ & PB1426 & NR & nptII & gus & $\begin{array}{l}\text { Expresión gus } \\
\text { transitoria }\end{array}$ & $\begin{array}{c}\text { Cunha y Barros, } \\
2002\end{array}$ \\
\hline 2003 & arabica & $\mathrm{SC}$ & pCAMBIA2301 & CaMV35S & nptII & gus & Integración del transgen & $\begin{array}{l}\text { Rosillo et al., } \\
2003\end{array}$ \\
\hline 2004 & arabica & $\mathrm{CE}$ & pBI-426 & CaMV35S & $n p t I I$ & gus & $\begin{array}{l}\text { Regeneración e } \\
\text { integración del transgen }\end{array}$ & Cunha et al., 2004 \\
\hline 2005 & canephora & ES & pCAMBIA3301 & CaMV35S & bar & gus & $\begin{array}{c}\text { Regeneración e } \\
\text { integración del transgen }\end{array}$ & Ribas et al., 2005 \\
\hline 2008 & arabica & $\mathrm{CE}$ & pCAMBIA2301 & CaMV35S & $n p t I I$ & gus & $\begin{array}{l}\text { Expresión } g u s \\
\text { transitoria }\end{array}$ & Gatica et al., 2008 \\
\hline \multirow[t]{2}{*}{2009} & arabica & $\mathrm{CE}$ & pBI426 & CaMV35S & $n p t I I$ & gus & $\begin{array}{c}\text { Regeneración e } \\
\text { integración del transgen }\end{array}$ & $\begin{array}{l}\text { Albuquerque et } \\
\text { al., } 2009\end{array}$ \\
\hline & arabica & Hojas y ES & pCAMBIA1305,2 & CaMV35S & $h p t$ & gus & $\begin{array}{l}\text { Expresión } g u s \\
\text { transitoria }\end{array}$ & Gatica et al., 2009 \\
\hline \multirow[t]{3}{*}{2010} & arabica & ES & pCAMBIA3201 & CaMV & bar & gus & $\begin{array}{l}\text { Expresión gus } \\
\text { transitoria y } \\
\text { regeneración }\end{array}$ & $\begin{array}{l}\text { De-Guglielmo et } \\
\text { al., } 2010 \mathrm{~b}\end{array}$ \\
\hline & arabica & ES torpedo & $\begin{array}{c}\text { pUBC } \\
\text { ubi-cry1ac-nos }\end{array}$ & Ubiquitina & NR & crylac & Integración del transgen & $\begin{array}{l}\text { De-Guglielmo et } \\
\text { al., 2010a }\end{array}$ \\
\hline & arabica & $\mathrm{CE}$ & pBIN19 $\alpha$ AI-1 & PHA-L & NR & $\alpha-\mathrm{AI} 1$ & $\begin{array}{c}\text { Regeneración, } \\
\text { integración del } \\
\text { transgen,generación } \mathrm{T} 1\end{array}$ & $\begin{array}{l}\text { Barbosa et al., } \\
2010\end{array}$ \\
\hline
\end{tabular}

CE: callos embriogénicos, EC: embriones cigóticos, ES: embriones somáticos, NR: no reportado, P: protoplastos, SH: segmentos de hoja, SC: suspensiones celulares / CE: embryogenic callus, EC: zygotic embryos, ES: somatic embryos, NR: not reported, P: protoplasts, SH: leaf segments, SC: cell suspensions. 
$4 \mathrm{mM}$ de cloruro de calcio dihidratado, $0,1 \mathrm{mM}$ de glucosa y $0,2 \mathrm{M}$ de espermidina) y un tiempo de descarga de 500 ms se obtuvo el mayor porcentaje de vitalidad (32,14\%). Sin embargo, al aplicar una capacitancia de 1000 y 1200 $\mu \mathrm{F}$ hubo mayores porcentajes de expresión transitoria del gen gus $(59,37$ y $61,01 \%$, respectivamente) con respecto al tratamiento electroporado con $490 \mu \mathrm{F}$ (50 \% de expresión transitoria) (Barbón et al., 2011).

\section{Biobalística}

La biobalística es uno de los métodos directos de transformación más ampliamente utilizado en plantas, y se basa en el uso de partículas de metales pesados biológicamente inertes como el oro o el tungsteno para transportar las moléculas de ácidos nucleicos. Se da un paso conocido como bombardeo o disparo, en el que estas partículas son aceleradas a gran presión con gases como helio o nitrógeno bajo condiciones establecidas (presión y distancia del disparo, cantidad de ácido nucleico) hacia el tejido blanco, lo cual permite la penetración de los ácidos nucleicos al genoma vegetal (López et al., 2013).

En café, el primer estudio con la técnica biobalística se remonta a 1995 (Cuadro 1), con diferentes tipos de explantes como hojas, embriones somáticos y suspensiones celulares de C. arabica L. y C. canephora P., y se determinó la expresión transitoria del gen gus controlada por dos promotores: EF1 $\alpha$-A1 de Arabidopsis thaliana y CaMV35S del virus del mosaico de la coliflor (Brassica oleracea var. botrytis L.). Se obtuvo una expresión observable en hojas y el promotor EF1 $\alpha$-A1, además, se concluyó que suspensiones celulares y embriones somáticos son poco apropiados para estudios de expresión transitoria gus, por presentar actividad endógena (VanBoxtel et al., 1995).

Regiones apicales de embriones cigóticos de C. arabica L. se bombardearon con tres plásmidos distintos: pB1426 (gen gus), pAG1 (gen gus y ahas para resistencia al herbicida Imazapyr) y pAA4 (gen inhibidor de $\alpha$-amilasa en insectos y gus) (información de promotores y terminadores no disponible). Se concluyó que a partir de la expresión transitoria del gen gus no existía diferencia entre los plásmidos utilizados. Además, obtuvieron expresión transitoria diferencial del gen gus dependiente del tiempo de cultivo de los embriones en medio WPM (Wood Plant Medium) (McCown y Lloyd, 1981) previos a su bombardeo, donde a los dos y ocho días de cultivo se observaron un mayor número de puntos azules con respecto a los cuatro y seis días (Barros et al., 2000).

Se evaluó la expresión transitoria del gen gus cuando se colocaron embriones cigóticos de $C$. arabica L. en cocultivo por distintos días $(2,5,7,9$ y 12 días) previos al bombardeo con un plásmido que contenía el gen gus, y se observó que a los doce días se optimizó su expresión (Barros et al., 2001).

Callos embriogénicos de $C$. arabica L. Catuaí Vermelho derivados de segmentos de hoja se transformaron genéticamente con el vector PB1426, el cual posee los genes gus y nptII, y posteriormente se subcultivaron semanalmente en medios de selección con concentraciones ascendentes (de 200 a 400 mg. $1^{-1}$ ) de kanamicina. Los callos que crecieron en el medio de selección con $400 \mathrm{mg} . \mathrm{l}^{-1}$ del antibiótico se utilizaron para realizar la prueba histoquímica gus, en la que todos los explantes mostraron una coloración azul positiva (información no disponible) (Cunha y Barros, 2002).

Suspensiones celulares de C. arabica L. se bombardearon con el gen gus controlado por el promotor constitutivo CAMV35S, donde al someter las células a un pretratamiento de cuatro horas antes del bombardeo en un medio con 0,5 M manitol-sorbitol, una presión de 1550 psi y $12 \mathrm{~cm}$ de distancia entre el explante y la fuente

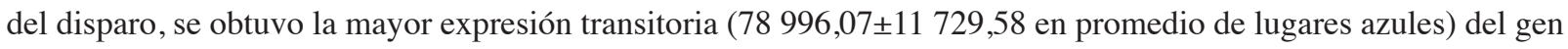
gus (Rosillo et al., 2003). Este protocolo se utilizó para comparar el promotor CAMV35S contra dos promotores de café ( $\alpha$-tubulina y arabicina) en endospermos de café, sin encontrarse diferencias significativas entre ellos, basados en la prueba histoquímica gus realizada a explantes bombardeados con los tres plásmidos, aunque solo el promotor CAMV35S y el de arabicina mostraron actividad gus. 
Callos embriogénicos de C. arabica L., se bombardearon con el plásmido pBI-426 (nptII y gus), y luego se seleccionaron con $400 \mathrm{mg} . \mathrm{l}^{-1}$ de kanamicina y se analizaron por PCR. Un día previo al bombardeo, los callos se colocaron en medio osmótico con $10 \mu \mathrm{M}$ de 2,4-D y 0,5 $\mathrm{M}$ de manitol para luego ser bombardeados y, posteriormente subcultivarse al mismo medio (sin manitol) por quince días, luego de los cuales se colocaron en selección. Se obtuvieron 88 plantas de 44 eventos, de las cuales a doce se les realizaron extracciones de ADN y posterior PCR para la amplificación de un fragmento del gen gus, con la presencia del gen en once de ellas. En este medio se produjeron embriones somáticos que se transfirieron a un medio WPM (McCown y Lloyd, 1981) y, posteriormente al invernadero. A estas plantas se les realizaron PCR para el gen gus, obteniéndose la amplificación del transgen (Cunha et al., 2004).

Cuando se bombardearon embriones somáticos de C. canephora P. con el plásmido pCAMBIA3301 que contenía los genes bar y gus, se obtuvo una transformación estable, confirmado por la prueba gus, PCR y southern blot para el gen bar (Ribas et al., 2005). Por su parte, en Costa Rica se determinaron las condiciones óptimas de presión de helio (900 y 1550 psi) y distancia del disparo $(9$ y $12 \mathrm{~cm}$ ), para realizar transformación mediante biobalística. Con el empleo de callos embriogénicos de C. arabica L. Catuaí, a una presión de 900 psi y una distancia de $9 \mathrm{~cm}$, Gatica et al. (2008) obtuvieron el mayor número de lugares con coloración azul característica de un resultado positivo en la prueba gus. Además, obtuvieron expresión estable del gen gus en callos bombardeados con el plásmido pCAMBIA2301 (uidA y $n p t I I$ ), sometidos a una selección con $100 \mathrm{mg} \cdot \mathrm{l}^{-1}$ del antibiótico kanamicina (Gatica et al., 2008).

Las condiciones óptimas de entrega de ADN con la técnica de biobalística, se determinaron en hojas y embriones somáticos de las variedades Caturra y Catuaí de C. arabica L. (Gatica et al., 2009). Como resultado se obtuvo que la mayor expresión transitoria del gen gus se dio cuando las hojas de ambas variedades y los embriones somáticos de Catuaí se cultivaron por $5 \mathrm{~h}$ en un medio complementado con $0,5 \mathrm{M}$ de manitol y 0,5 M de sorbitol. Además, la combinación de una presión de 1100 psi y una distancia de $9 \mathrm{~cm}$, generó la mayor cantidad de puntos azules en la prueba gus para las hojas de Caturra $(23,6 \pm 3,9)$, mientras que para Catuaí, la misma presión y distancias de 6 y $9 \mathrm{~cm}$ dio los mejores resultados $(10,2 \pm 1,9$ y $8,2 \pm 1,9$, respectivamente). Posteriormente, con el protocolo optimizado y tres plásmidos diferentes: pCAMBIA 1301 y pCAMBIA 1305,2 con los genes hpt y gus, y pCAMBIA 1301-BAR ( $g$ us y bar), se realizó una transformación y se obtuvo el mayor número de puntos azules de la prueba gus en la variedad Catuaí $(28,9 \pm 4,3)$ y Caturra $(54,6 \pm 5,7)$, al bombardear hojas con el plásmido pCAMBIA 1305,2 .

En 2009, callos embriogénicos derivados de segmentos de hoja de C. arabica L. se bombardearon con el vector pBI426 (nptII y gus) dirigido por el promotor doble CaMV35S. Posteriormente, en medio de selección con kanamicina se obtuvieron embriones somáticos que resultaron positivos para la prueba histoquímica gus, $\mathrm{y}$ amplificaron un fragmento específico del gen nptII por PCR. Además, por medio de la técnica de southern blot se obtuvo un número bajo de copias integradas del gen nptII. Finalmente, los embriones somáticos se desarrollaron a plantas, en las que las flores y frutos fueron positivas para la prueba gus, demostrando una transformación estable (Albuquerque et al., 2009).

Se bombardearon embriones somáticos de C. arabica L. cv. Catimor en estado torpedo con el gen reportero gus, con el fin de determinar las condiciones óptimas de presión, distancia de disparo, supervivencia, así como el efecto de una pre-incubación de los embriones en medio líquido de regeneración suplementado con 8 mg..$^{-1}$ de ácido naftalenacético (ANA) antes de su regeneración en medio sólido (De-Guglielmo et al., 2010b). Se encontró que los mejores resultados de expresión gus se dieron al utilizar una presión de 70 psi de helio, $14 \mathrm{~cm}$ de distancia y colocando los explantes bombardeados directamente en el medio sólido sin pasar por el medio líquido. Además, se han realizado transformaciones por este método para introducir genes de resistencia a insectos, como por ejemplo, genes crylac de Bacillus thuringiensis (Bt) en el genoma de $C$ arabica L. cv. Catimor con el plásmido pUBC o el cassette ubi-crylac-nos, los cuales no contienen genes marcadores, obteniendo plantas positivas por PCR, southern blot y RT-PCR para el gen crylac (De-Guglielmo et al., 2010a). 
Se ha logrado inhibir enzimas de insectos, como por ejemplo la $\alpha$-amilasa de la broca del café (Hypothenemus hampei Ferrari), al transformar por biobalística callos embriogénicos de $C$. arabica L. con el plásmido pBIN19 $\alpha$ AI-1 que contenía el gen inhibidor de amilasa $\alpha$ AI-1 proveniente de Phaseolus vulgaris L. controlado por un promotor específico de semilla (PHA-L). Se obtuvieron seis plantas regeneradas que fueron positivas a análisis por PCR de un fragmento del gen $\alpha$ AI-1. Luego, se realizaron ensayos in vitro de inhibición de la $\alpha$ amilasa de un extracto proteico de la broca, por medio de extractos de la proteína $\alpha \mathrm{AI}-1$ de las plantas regeneradas, obteniéndose resultados de hasta $88 \%$ de inhibición de la actividad enzimática (Barbosa et al., 2010).

\section{Métodos biológicos indirectos de transformación genética}

En protocolos de transformación genética por medios biológicos se han utilizado las bacterias Agrobacterium tumefaciens y Agrobacterium rhizogenes. Estas son bacterias Gram negativas, encapsuladas y con forma de bastón (bacilo), con una temperatura óptima de crecimiento de $25-28{ }^{\circ} \mathrm{C}$, las cuales son fitopatógenos del suelo (Nester, 2015). A.tumefaciens ha sido estudiada ampliamente, ya que logra transferir naturalmente secciones específicas de su ADN a células huésped (Morillo, 2011), causando el tumor del cuello o agalla que crece en la unión de la raíz y el tallo (cuello), la cual es una enfermedad agronómica importante que afecta en su mayoría a plantas dicotiledóneas.

La región de ADN transferida (ADN-T) se encuentra alojada en la bacteria dentro del plásmido inductor de tumores Ti (en A.tumefaciens) y dentro del plásmido Ri (en A.rhizogenes), los cuales codifican genes relacionados con la síntesis de reguladores de crecimiento (auxinas y citocininas), y producción de opinas (octopinas, nopalinas, lisopinas), las cuales son fuentes de carbono y nitrógeno para la bacteria (Llop, 2003).

Con el conocimiento básico sobre cómo se da la transferencia del ADN-T a las plantas, se han desarrollado vectores con el fin de introducir genes foráneos en plantas cultivadas. Los genes codificantes para la síntesis de opinas y auxinas, al no ser necesarios para la transferencia del ADN-T, son reemplazados por los genes de interés. Mayoritariamente se utilizan vectores binarios, los cuales consisten en diferentes plásmidos dentro de una misma bacteria: un plásmido helper que lleva los genes de virulencia (genes vir) necesarios para la transferencia del ADN-T de la bacteria al genoma vegetal, pero que no son transferidos a la planta, y un plásmido que lleva los genes de interés a ser transferidos (Valderrama et al., 2005).

\section{Agrobacterium rhizogenes}

La especie bacteriana Agrobacterium rhizogenes se ha utilizado en café (Cuadro 2), mayoritariamente para el análisis funcional de genes relacionados con resistencia al nematodo de la raíz (Meloidogyne coffeicola) (Alpizar et al., 2007). Fue utilizada inicialmente en este cultivo en el año 1993 (Spiral et al., 1993) y luego en 1997 (Leroy et al., 1997), en estos trabajos se transformaron embriones somáticos de C. canephora P. con la cepa A4 (genes gus y nptII), obteniéndose plantas transgénicas. Además de la cepa A4, se ha utilizado la cepa IFO14554 en segmentos de hoja de C. arabica L., con la que se obtuvo la integración de los transgenes pero no la regeneración de embriones somáticos (Sugiyama et al., 1995).

Protocolos para transformar $C$. arabica $\mathrm{L}$. han sido desarrollados, en los cuales se ha obtenido una regeneración tres veces más rápida (cinco meses) de raíces transformadas a partir de hipocótilos de embriones cigóticos (Alpizar et al., 2006). También, se han descrito protocolos para la transformación de embriones somáticos secundarios de C. canephora P. con un paso de sonicación, que consiste en colocar los embriones somáticos en una solución de $A$. rhizogenes y ultrasonicarlos por $30 \mathrm{~s}$ a $80 \%$ de amplitud y luego colocarlos en agitación a 120 rpm por 2 h, para posteriormente cultivarlos en medio semisólido de regeneración (Kumar et al., 2006). 
Cuadro 2. Resumen de estudios de transformación con A. rhizogenes en café. 1993-2009.

Table 2. Summary of transformation studies with A. rhizogenes in coffee. 1993-2009.

\begin{tabular}{|c|c|c|c|c|c|c|c|c|c|}
\hline \multicolumn{10}{|c|}{ Agrobacterium rhizogenes } \\
\hline Año & Coffea & Explante & Cepa & Vector & Promotor & Gen selec. & $\begin{array}{l}\text { Gen } \\
\text { interés }\end{array}$ & Resultados & Referencia \\
\hline 1993 & $\begin{array}{c}\text { arabica } \\
\text { canephora }\end{array}$ & $\mathrm{ES}$ & A4 & pBIN 19 & CaMV35S & $n p t$ & gus & $\begin{array}{l}\text { Comprobación } \\
\text { de la integración } \\
\text { del transgen y } \\
\text { regeneración de PT }\end{array}$ & $\begin{array}{l}\text { Spiral et al., } \\
1993\end{array}$ \\
\hline 1995 & arabica & $\mathrm{SH}$ & IFO14554 & NR & NR & NR & NR & $\begin{array}{c}\text { Integración del } \\
\text { transgen. No } \\
\text { regeneración }\end{array}$ & $\begin{array}{l}\text { Sugiyama et } \\
\text { al., } 1995\end{array}$ \\
\hline 1996 & canephora & ES & A4 & pBIN19 & NR & $\operatorname{csr}-1-1$ & crylAc & $\begin{array}{l}\text { Comprobación } \\
\text { de la integración } \\
\text { del transgen y } \\
\text { regeneración de PT }\end{array}$ & $\begin{array}{l}\text { Giménez et } \\
\text { al., } 1996\end{array}$ \\
\hline \multirow[t]{2}{*}{2006} & $\begin{array}{c}\text { arabica } \\
\text { canephora }\end{array}$ & $\mathrm{H}$ de $\mathrm{EC}$ & A4 & pCAMBIA2300 & CaMV35S & Visual & $g f p$ & $\begin{array}{l}\text { Regeneración de } \\
\text { raíces transformadas }\end{array}$ & $\begin{array}{l}\text { Alpizar et } \\
\text { al., } 2006\end{array}$ \\
\hline & canephora & $\mathrm{ES}$ & A4 & pCAMBIA1301 & CaMV35S & $h p t$ & gus & $\begin{array}{l}\text { Comprobación } \\
\text { de la integración } \\
\text { del transgen y } \\
\text { regeneración de PT }\end{array}$ & $\begin{array}{c}\text { Kumar et } \\
\text { al., } 2006\end{array}$ \\
\hline 2007 & arabica & $\mathrm{H}$ & A4 & pBIN19 & CaMV35S & Visual & gus & $\begin{array}{l}\text { Comprobación } \\
\text { de la integración } \\
\text { del transgen y } \\
\text { regeneración de PT }\end{array}$ & $\begin{array}{l}\text { Alpizar et } \\
\text { al., } 2007\end{array}$ \\
\hline 2008 & arabica & $\mathrm{EC}$ & A4-RS & Root Inducing & NR & rol y aux & NR & $\begin{array}{l}\text { Proliferación de } \\
\text { raíces peludas }\end{array}$ & $\begin{array}{l}\text { Alpizar et } \\
\text { al., } 2008\end{array}$ \\
\hline 2009 & arabica & $\mathrm{H}$ & MSU440 & $\begin{array}{c}\text { pCAMBIA1301 } \\
\text { pMOG22- } \\
\text { 35S:SHN2 } \\
\text { pREDRoot }\end{array}$ & NR & $\begin{array}{c}h p t \\
n p t \\
\text { Fluorescencia }\end{array}$ & $\begin{array}{c}\text { gus } \\
---- \\
\text { dsRed }\end{array}$ & $\begin{array}{l}\text { Integración del } \\
\text { transgen. Quimera } \\
\text { con meristemos } \\
\text { silvestres y raíces } \\
\text { transgénicas }\end{array}$ & Stein, 2009 \\
\hline
\end{tabular}

H: hipocótilos, EC: embriones cigóticos, ES: embriones somáticos, NR: no reportado, PT: plantas transgénicas, SH: segmentos de hoja / H: hypocotyls, EC: zygotic embryos, ES: somatic embryos, NR: not reported, PT: transgenic plants, SH: leaf segments.

En el 2008, se determinó la concentración de auxinas en el medio de cultivo para la proliferación de raíces peludas o hairy roots de C. arabica L. obtenidas posterior a la transformación con la cepa A4-RS (rol y aux), donde con $0,5 \mu \mathrm{M}$ de AIB se obtuvo el mayor crecimiento y ramificación con respecto a los tratamientos con 0, 0,125, 0,25 y 5 de la auxina (Alpizar et al., 2008).

En 2009, se desarrolló un método de transformación para generar una C. arabica L. quimera compuesta por meristemos no transgénicos y raíces transgénicas. Para lo cual, a los hipocótilos se les hizo una pequeña incisión en la que se colocó una colonia de A. rhizogenes que contenía uno de los siguientes plásmidos: pCAMBIA1301 (gus y hptII bajo el control del promotor CaMV35S), pMOG22-35S::SHN2 (shine2 y hptII) o el pREDRoot con los genes DSRED1 (codifica para la proteína roja fluorescente) y nptII bajo el control del promotor CaMV35S. Luego de este paso, se colocaron los explantes en medio semisólido Murashige \& Skoog. Para analizar las plantas incubadas con el plásmido pCAMBIA1301, se utilizó la prueba de expresión transitoria gus, donde se obtuvo una eficiencia de transformación de $30 \%$. Para el plásmido pMOG22-35S::SHN2 se utilizó la técnica de PCR, obteniéndose una eficiencia de $35 \%$, y para el gen DsREDl del plásmido pREDRoot se utilizó un estereomicroscopio de fluorescencia con eficiencias de $42 \%$ (Stein, 2009). 


\section{Agrobacterium tumefaciens}

Los protocolos de transformación disponibles en café utilizan mayoritariamente Agrobacterium tumefaciens (Cuadros 3 y 4), por ser un método barato que transfiere segmentos largos de ADN y con un número bajo de copias del gen integradas (Ribas et al., 2006c).

Las investigaciones con esta bacteria en café iniciaron en los años noventa, cuando Ocampo y Manzanera (1991) infectaron hipocótilos de C. arabica L. con A.tumefaciens (cepa no especificada) sin lograr la regeneración de plantas. Además, en 1999, Hatanaka et al. (1999) reportaron la transformación de callos embriogénicos de $C$.

Cuadro 3. Resumen de estudios de transformación con Agrobacterium tumefaciens en café del año 1991 al 2005.

Table 3. Summary of transformation studies with Agrobacterium tumefaciens in coffee from 1991 to 2005.

\begin{tabular}{|c|c|c|c|c|c|c|c|c|c|}
\hline \multirow[b]{2}{*}{ Año } & \multicolumn{9}{|c|}{ Agrobacterium tumefaciens } \\
\hline & Coffea & Explante & Cepa & Vector & Promotor & Gen selec. & $\begin{array}{l}\text { Gen } \\
\text { interés }\end{array}$ & Resultados & Referencias \\
\hline \multirow[t]{2}{*}{1991} & arabica & $\mathrm{H}$ & NR & NR & NR & NR & NR & No regeneración & $\begin{array}{c}\text { Ocampo y } \\
\text { Manzanera, } \\
1991\end{array}$ \\
\hline & arabica & $\mathrm{P}$ & NR & pGV2260 & CaMV35S & $h p t$ & gus & $\begin{array}{l}\text { Expresión gus } \\
\text { transitoria }\end{array}$ & $\begin{array}{c}\text { Spiral y } \\
\text { Petieard, } \\
1991\end{array}$ \\
\hline 1999 & canephora & $\mathrm{CE}$ & EHA101 & pIG121-Hm & NR & $h p t$ у $n p t I I$ & gus & $\begin{array}{l}\text { Comprobación } \\
\text { de la integración } \\
\text { del transgen y } \\
\text { regeneración de PT }\end{array}$ & $\begin{array}{l}\text { Hatanaka et } \\
\text { al., } 1999\end{array}$ \\
\hline \multirow[t]{2}{*}{2000} & $\begin{array}{c}\text { arabica } \\
\text { canephora }\end{array}$ & ES & LBA4404 & pBIN19 & $E F-1 \alpha$ & $\operatorname{csr} r-1-1$ & crylac & $\begin{array}{l}\text { Comprobación } \\
\text { de la integración } \\
\text { del transgen y } \\
\text { regeneración de PT }\end{array}$ & $\begin{array}{l}\text { Leroy et al., } \\
\quad 2000\end{array}$ \\
\hline & $\begin{array}{l}\text { arabica } \\
\text { canephora }\end{array}$ & CE y ES & LBA4404 & pBIN19 & $E F-1 \alpha$ & $\operatorname{csr}-1-1$ & $\begin{array}{c}\text { gus } \\
\operatorname{crylA}(c)\end{array}$ & $\begin{array}{l}\text { Comprobación } \\
\text { de la integración } \\
\text { del transgen y } \\
\text { regeneración de PT }\end{array}$ & $\begin{array}{l}\text { Dufour et } \\
\text { al., } 2000\end{array}$ \\
\hline \multirow[t]{2}{*}{2002} & canephora & $\begin{array}{l}\mathrm{H}, \mathrm{ES} \text { y } \\
\text { EC }\end{array}$ & EHA101 & pBECKS400 & CaMV35S & $h p t$ & gus & $\begin{array}{l}\text { Integración del } \\
\text { transgen }\end{array}$ & $\begin{array}{l}\text { Mishra et } \\
\text { al., } 2002\end{array}$ \\
\hline & $\begin{array}{c}\text { arabica } \\
\text { canephora }\end{array}$ & ES y CE & EHA101 & pHIBI-IG & CaMV35S & $h p t$ & $\begin{array}{c}g f p, \\
\text { CaMXMT1 }\end{array}$ & $\begin{array}{l}\text { Supresión de } \\
\text { expresión por ácido } \\
\text { ribonucleico (ARN) } \\
\text { de interferencia y } \\
\text { regeneración de PT }\end{array}$ & $\begin{array}{l}\text { Ogita et al., } \\
2004\end{array}$ \\
\hline \multirow[t]{3}{*}{2004} & canephora & $\mathrm{H}$ & EHA101 & pBECKS400 & CaMV35S & hpt & gus & $\begin{array}{l}\text { Comprobación } \\
\text { de la integración } \\
\text { del transgen y } \\
\text { regeneración de PT }\end{array}$ & $\begin{array}{l}\text { Mishra y } \\
\text { Sreenath, } \\
2004\end{array}$ \\
\hline & canephora & $\mathrm{CE}$ & EHA105 & pCAMBIA3301 & CaMV35S & $p p t$ & gus & $\begin{array}{l}\text { Integración del } \\
\text { transgen }\end{array}$ & $\begin{array}{l}\text { Cruz et al., } \\
2004\end{array}$ \\
\hline & canephora & ES & $\begin{array}{c}\text { A4 } \\
\text { EHA101 }\end{array}$ & pCAMBIA1381 & CaMV35S & $h p t$ & NMT & $\begin{array}{c}\text { Supresión de } \\
\text { expresión por ARNi }\end{array}$ & $\begin{array}{l}\text { Kumar et } \\
\text { al., } 2004\end{array}$ \\
\hline 2005 & canephora & ES & LBA4404 & pBIN19 & $\mathrm{pEF} 1 \alpha$ & $\operatorname{csr} r-1-1$ & crylAc & Pruebas de campo & $\begin{array}{l}\text { Perthuis et } \\
\text { al., } 2005\end{array}$ \\
\hline
\end{tabular}

CE: callos embriogénicos, H: hipocótilos, EC: embriones cigóticos, ES: embriones somáticos, NR: no reportado, P: protoplastos, PT: plantas transgénicas / CE: embryogenic callus, H: hypocotyls, EC: zygotic embryos, ES: somatic embryos, NR: not reported, P: protoplasts, PT: transgenic plants. 
Cuadro 4. Resumen de estudios de transformación con Agrobacterium tumefaciens en café del año 2006 al 2011.

Table 4. Summary of transformation studies with Agrobacterium tumefaciens in coffee from 2006 to 2011.

\begin{tabular}{|c|c|c|c|c|c|c|c|c|c|}
\hline \multirow[b]{2}{*}{ Año } & \multicolumn{9}{|c|}{ Agrobacterium tumefaciens } \\
\hline & Coffea & Explante & Cepa & Vector & Promotor & Gen selec. & Gen interés & Resultados & Referencias \\
\hline \multirow[t]{3}{*}{2006} & arabica & $\mathrm{CE}$ & EHA105 & pCAMBIA3300 & CaMV35S & bar & $\begin{array}{c}\text { ACC- } \\
\text { oxidasa }\end{array}$ & $\begin{array}{l}\text { Expresión } \\
\text { antisentido }\end{array}$ & $\begin{array}{c}\text { Ribas et al., } \\
2006 \mathrm{a}\end{array}$ \\
\hline & canephora & CE y SH & C58 & pER10W-35SRed & CaMV35S & nptII & $D S R F P$ & $\begin{array}{l}\text { Comprobación } \\
\text { de la integración } \\
\text { del transgen y } \\
\text { regeneración de PT }\end{array}$ & $\begin{array}{l}\text { Canche et } \\
\text { al., } 2006\end{array}$ \\
\hline & canephora & SH & EHA105 & pCAMBIA3301 & CaMV35S & bar & gus & $\begin{array}{l}\text { Comprobación } \\
\text { de la integración } \\
\text { del transgen y } \\
\text { regeneración de PT }\end{array}$ & $\begin{array}{c}\text { Ribas et al., } \\
2006 \mathrm{~b}\end{array}$ \\
\hline \multirow[t]{2}{*}{2008} & canephora & ES & $\mathrm{C} 58 \mathrm{C} 1$ & pER10W-35SRED & CaMV35S & wuschel & $d s r f p$ & $\begin{array}{l}\text { Comprobación } \\
\text { de la integración } \\
\text { del transgen y } \\
\text { regeneración de PT }\end{array}$ & $\begin{array}{c}\text { Arroyo et } \\
\text { al., } 2008\end{array}$ \\
\hline & $\begin{array}{c}\text { arabica } \\
\text { canephora }\end{array}$ & CE y SH & $\begin{array}{l}\text { EHA101 } \\
\text { EHA105 } \\
\text { AGL1 } \\
\text { LBA4404 }\end{array}$ & pBECKS2000 & CaMV35S & $h p t$ & gus y $g f p 5$ & $\begin{array}{l}\text { Comprobación } \\
\text { de la integración } \\
\text { del transgen y } \\
\text { regeneración de PT }\end{array}$ & $\begin{array}{c}\text { Mishra et } \\
\text { al., } 2008\end{array}$ \\
\hline \multirow[t]{2}{*}{2010} & canephora & $\mathrm{H}$ & GV3101 & pCAMBIA1305.2 & CaMV35S & $h p t$ & gus & $\begin{array}{l}\text { Comprobación } \\
\text { de la integración } \\
\text { del transgen y } \\
\text { regeneración de PT }\end{array}$ & $\begin{array}{c}\text { Sridevi et } \\
\text { al., } 2010\end{array}$ \\
\hline & canephora & $\mathrm{SC}$ & EHA105 & pBECKS2000.7 & CaMV35S & $h p h$ & $s g f p$ & $\begin{array}{l}\text { Comprobación } \\
\text { de la integración } \\
\text { del transgen y } \\
\text { regeneración de PT }\end{array}$ & $\begin{array}{c}\text { Mishra et } \\
\text { al., } 2010\end{array}$ \\
\hline 2011 & arabica & $\mathrm{CE}$ & LBA1119 & pMDC32 & CaMV35S & hptII & gfp5 & $\begin{array}{l}\text { Comprobación } \\
\text { de la integración } \\
\text { del transgen y } \\
\text { regeneración de PT }\end{array}$ & $\begin{array}{c}\text { Ribas et al., } \\
\quad 2011\end{array}$ \\
\hline
\end{tabular}

CE: callos embriogénicos, H: hipocótilos, ES: embriones somáticos, PT: plantas transgénicas, SH: segmentos de hoja, SC: suspensiones celulares / CE: embryogenic callus, H: hypocotyls, ES: somatic embryos, PT: transgenic plants, SH: leaf segments, SC: cell suspensions.

canephora P. con los genes gus, hpt y nptII, quienes luego de realizar la selección de los callos transformados con $100 \mathrm{mg} . \mathrm{l}^{-1}$ de higromicina, y la prueba histoquímica gus, obtuvieron una reacción positiva demostrada por puntos azules en los explantes. Los embriones somáticos formados a partir de este callo se desarrollaron en plántulas, las cuales presentaron resultados positivos para la prueba gus y amplificaron por PCR fragmentos específicos de los genes hpt y gus (Hatanaka et al., 1999).

Uno de los trabajos iniciales más importantes en transformación de este cultivo con genes de interés agronómicos fue logrado por Leroy et al. (2000), al obtener plantas transgénicas resistentes al minador de la hoja, mediante la transformación de embriones somáticos de C. arabica L. y C. canephora P. con A. tumefaciens LBA4404 portadora del gen crylac de Bacillus thuringiensis. Además, se publicó una metodología de transformación de callos embriogénicos y embriones somáticos de dos genotipos de C. arabica L. (Catimor 8661-4 y Et29 x Ca5) y dos de C. canephora P. (126 y 197), con la cepa LBA4404 y un plásmido que contenía los genes gus, csr 1-1, que confiere resistencia al clorosulfurón, y crylA(c) de Bacillus thuringiensis dirigidos por el promotor EF-la. Para cada 
genotipo se obtuvo una eficiencia de transformación aproximada al $1 \%$, los embriones somáticos que crecieron en el medio selectivo con clorosulfurón se analizaron molecularmente por PCR y por medio de la prueba histoquímica gus, dando resultados positivos de la presencia del gen $c s r-1$ y la expresión del gen gus, respectivamente (Dufour et al., 2000).

En 2002, Mishra et al. (2002), transformaron segmentos de hoja, hipocótilos, embriones cigóticos y somáticos de C. canephora con un plásmido que contenía el gen gus, y se analizó por medio de la prueba histoquímica gus la localización de la expresión transitoria en los explantes. Se determinó que los extremos de las venas en las hojas y las regiones adyacentes de hipocótilos y ambos tipos de embriones, fueron los sitios de expresión transitoria del gen.

Mediante el uso de A.tumefaciens, también se ha estudiado la ruta metabólica de síntesis de cafeína. Se introdujeron ARN de interferencia en plantas de C. arabica L. y C. canephora P., por medio de A. tumefaciens para suprimir la expresión de los genes CaMXMT1, CaXMT1 y CaDXMT1, y evaluar si esta supresión afecta el contenido de cafeína en las plantas, para con esto en un futuro producir café libre de cafeína. Las líneas transgénicas presentaron una reducción de 30-50\% en los transcritos de los tres genes en comparación con las plantas control no transformadas (Ogita et al., 2004).

En el 2004, se publicaron dos metodologías para obtener altas eficiencias en el cultivo de café. En la primera se utilizaron hipocótilos de los cultivares S274 y CxR de C. canephora P., se transformaron con la cepa EHA101, con el plásmido pBECKS ( $g u s$, nptII y el gen de resistencia a la higromicina $h p t$ ). Al colocar los explantes en un medio de precultivo MS complementado con $0,1 \mathrm{mg} . \mathrm{l}^{-1}$ de 2,4-D + $1 \mathrm{mg} . \mathrm{l}^{-1}$ de ácido indol-acético (AIA) + $4 \mathrm{mg} . \mathrm{l}^{-1}$ de kinetina por tres días en oscuridad y luego en cocultivo a $22^{\circ} \mathrm{C}$, se obtuvieron plantas transformadas establemente de ambos cultivares (Mishra y Sreenath, 2004). En la segunda metodología se utilizaron callos embriogénicos de C. canephora P. y se transformaron con la cepa EHA105, que contiene un plásmido con los genes ppt (resistencia a la fosfinotricina) y gus bajo el control del promotor CAMV35S. Luego de dos meses de cultivo de los callos transformados, se obtuvieron embriones somáticos en estado torpedo que expresaban el gen gus, determinado por prueba histoquímica, 54 embriones se aclimataron, para luego confirmar por PCR la integración estable del gen gus en todas las muestras (Cruz et al., 2004).

En la Guyana Francesa se llevaron a cabo pruebas controladas de campo con plantas de C. canephora P. transformadas con el gen cryl Ac de Bacillus thuringiensis (Bt), gen de resistencia al minador de la hoja (Leucoptera coffeella), dirigido por el promotor constitutivo $\mathrm{pEF} 1 \alpha$. Se sembraron veinte plantas transformadas y sesenta plantas control no transformadas, durante un período de cuatro años desde su siembra se realizaron seis liberaciones de $L$. coffeella, durante las cuales se contó el número de minas o áreas necróticas características del ataque del minador. Las plantas transformadas presentaron menos del $10 \%$ del número promedio de minas de las plantas control, con lo que se concluyó que se estaba dando una expresión estable del transgen (Perthuis et al., 2005).

En 2006 se obtuvieron plantas transgénicas de C. canephora L. resistentes al herbicida glufosinato de amonio, luego de transformar segmentos de hoja con A. tumefaciens EHA105, la cual contenía el plásmido pCAMBIA3301 con el promotor 35S controlando los genes bar y uidA (Ribas et al., 2006b). En ese mismo año y con el mismo tipo de explante, se insertaron los genes npt y el de la proteína roja fluorescente ( $d s r f p$ ), por medio de infiltración al vacío, luego del paso de embriogénesis somática y selección del material transgénico, se obtuvo un rendimiento de $33 \%$ de embriones somáticos transformados (Canche et al., 2006).

La introducción del gen wuschel (WUS) en C. canephora L. con el empleo de A. tumefaciens $\mathrm{C} 58 \mathrm{C} 1$, ha contribuido al estudio del proceso de embriogénesis somática. Se han insertado genes como el wuschel y el dsrfp (que codifica para la proteína roja fluorescente) en embriones somáticos, y se determinó que la expresión de WUS podía inducir la formación de callos y aumentar la producción de embriones somáticos en un $400 \%$, con respecto a la inducción generada a partir de segmentos de hoja de explantes control no transformados. Además, los embriones transformados aumentaron en $350 \%$ su tamaño, pero no lograron regenerar, mostrando que la sobreexpresión o expresión continua de WUS resulta en malformaciones y alteraciones de crecimiento (Arroyo et al., 2008). 
Con el uso de los genes gus, sgfp, hpt y nptII en cuatro cepas de A. tumefaciens (EHA101, EHA105, AGL1 y LBA4404), se realizaron ensayos de transformación en los que se utilizaron callos embriogénicos derivados de hipocótilos y segmentos de hojas de vitroplantas. De acuerdo a los resultados de expresión transitoria del gen gus (información no disponible), se determinó que las cepas EHA101 y EHA105 eran mejores que las AGL1 y la LBA4404; además, con la cepa EHA105 se obtuvieron mayor cantidad de plantas transgénicas, lo cual se confirmó con pruebas moleculares de PCR para los genes hpt, gus y nptII y southern blot (Mishra et al., 2008).

En 2010 se reportó la transformación de hipocótilos con la cepa GV3101, portando el plásmido pCAMBIA1305.2 con los genes gus y hpt. Se obtuvo un porcentaje de transformación estable entre 2 y $5 \%$ (Sridevi et al., 2010). Otra publicación del mismo año (Mishra et al., 2010) enfatizó la importancia del gen de la proteína verde fluorescente $(g f p)$ para realizar la selección del tejido que contiene los genes de interés. Se transformaron suspensiones celulares de C. canephora L. con un vector pBECKS2000.7 ( $s g f p$ y $h p h$ ), y se determinó la eficiencia de realizar la selección visual junto con una baja concentración de antibiótico o con solamente una concentración mayor del mismo. Se concluyó que la selección con GFP y una concentración baja del agente selectivo, mejoraron la eficiencia y número de plantas transformadas; además, redujo el tiempo de formación de embriones somáticos transformados en diez semanas, comparado a una selección basada solamente en el antibiótico (Mishra et al., 2010).

Para la transformación genética en $C$. arabica L., se han utilizado ampliamente callos embriogénicos derivados de hoja, donde se han optimizado condiciones de transformación en términos de edad y fenotipo del explante, así como densidad óptica, tiempo y temperatura del cocultivo de la bacteria. Así, con el empleo de la cepa LBA1119, que contiene el plásmido pBIN35S GFP con el gen reportero $g f p 5$ bajo el control del promotor constitutivo CAMV35S, se determinó que callos embriogénicos friables de color amarillo con una edad entre 7 y 10 meses de proliferación, y una densidad óptica de 0,6 con un tiempo de cocultivo de cinco días a $20{ }^{\circ} \mathrm{C}$, era el conjunto óptimo de condiciones para realizar la integración de genes de interés. Con estas condiciones se utilizó la cepa LBA1119, la cual contenía el plásmido pMDC32 ( $g f p 5$ y hptII), en una nueva transformación de callos embriogénicos, obteniéndose una eficiencia mayor al $90 \%$ de transformación y conversión de callos a embriones somáticos y posteriormente a plantas, las cuales amplificaron fragmentos del gen hptII por PCR. Asimismo, por medio de southern blot se determinó que el $69 \%$ de las plantas presentaba una única copia del ADN-T en su genoma (Ribas et al., 2011).

\section{Nuevas tecnologías: edición de genomas mediante CRISPR-Cas9}

Una de las nuevas tecnologías con potencial uso en programas de mejoramiento genético vegetal no convencional es la técnica de repeticiones palindrómicas cortas agrupadas y regularmente interespaciadas (CRIPSR-Cas9, por sus siglas en inglés). Esta permite el corte de una molécula de ADN de manera precisa y controlada, logrando modificar la secuencia del genoma al eliminar o insertar nuevo ADN (Ran et al., 2013). Este mecanismo es utilizado por muchas bacterias como un sistema inmune que las protege de ácidos nucleicos externos de virus o plásmidos, en el cual se incorporan al genoma bacteriano secuencias del ADN invasor (ADN espaciador) entre repeticiones de una secuencia corta. Los transcritos de estos ADN espaciadores procesados como ARNcr se hibridan con un segundo ARN conocido como ARNtracr (transactivador de CRISPR), formando un complejo el cual se une a la enzima caspasa 9 (Cas9) y la guían hasta el ADN blanco en la que esta realizan los cortes (Sander y Joung, 2014).

En la actualidad, a nivel de laboratorio se genera un ARN guía (ARNg), resultado de la fusión del ARNcr del gen que se quiere modificar y el ARNtracr, y se inserta junto con la enzima Cas9 en la célula receptora que posee el genoma que se quiere modificar, donde la nucleasa realiza los cortes en la secuencia de ADN complementario al ARNcr especificado (Lammoglia et al., 2016). Posterior al corte del ADN realizado por la caspasa 9 en el sitio especificado para lograr introducir los cambios deseados en el genoma, se hace necesario manipular a los 
mecanismos naturales de reparación del ADN de una célula mediante dos formas (Sander y Joung, 2014): i) el método de unión de extremos no homólogos que consiste en pegar y unir los dos cortes hechos, lo que tiende a introducir errores, ya que los nucleótidos son aleatoriamente insertados o eliminados, y genera mutaciones que podrían modificar la funcionalidad de un gen, y ii) el método en el que la célula utiliza una cadena corta de ADN como plantilla para rellenar el espacio dejado por el corte de la caspasa 9, esta plantilla le es suministrada a la célula y con esto integra la secuencia que se desea para modificar la secuencia del genoma. Este sistema comparado con el mejoramiento genético convencional, posee la gran ventaja de que los cambios se realizan en genes específicos de loci nativos del genoma (Liu et al., 2017), por lo que, las células editadas se pueden comparar en términos genéticos con células y posteriores plantas desarrolladas por métodos de fitomejoramiento asistido por mutaciones, así con esto no tener que pasar por todas las políticas reglamentarias que por ejemplo enfrentan los cultivos OGM (AMC, 2016).

Para el uso de esta herramienta de edición de genomas mediante CRISPR-Cas9 en el cultivo del café, se necesita conocer exactamente los genes específicos para las características que se quieren alterar, por lo que, se han buscado genes candidatos para su posterior uso como genes blanco (Sant'Ana et al., 2018). Al respecto, Souto et al. (2016) reportaron la identificación de genes candidatos para tolerancia a sequía al comparar las respuestas moleculares a este factor en dos cultivares comerciales de C. arabica L.: IAPAR59 (tolerante a la sequía) y Rubi (susceptible). Estas variedades crecieron en campo bajo condiciones control con irrigación, y en condiciones de sequía, se analizaron 38 genes candidatos a través de la pirosecuenciación de ARN de sus ápices. Bajo condiciones de sequía se observó una regulación positiva en el cultivar IAPAR59 pero no en Rubi, para los genes que codifican proteínas para transferencia de lípidos (nsLTP), así como la CaSTK1 (proteína kinasa), CaMAS1 (biosíntesis de ácido abscísico), CaSLP1 (desarrollo de la planta) y CaSAMT1 (metiltransferasa dependiente de S-adenosil metionina).

Además de los factores bióticos, la calidad de taza es muy importante comercialmente y en ella intervienen compuestos lipídicos diterpenos como el cafestol y el kahweol, por lo que, se ha estudiado la síntesis de los mismos. Se estudió el contenido de estos diterpenos en varios tejidos de la planta de $C$. arabica L. como las raíces, hojas, flores y frutos, donde no se detectó ninguno en hojas, en raíces hubo mayor cantidad de kahweol, mientras que los niveles de cafestol fueron mayores en flores en comparación con los frutos. Utilizando genes del citocromo P450, se realizaron análisis transcripcionales de hojas, flores y frutos, a los 90, 120 y 150 días después de la floración, donde los genes $C a C Y P 76 C 4$, CaCYP82C2 y CaCYP74A1 mostraron patrones de transcripción similares para la concentración de cafestol y los genes CaCYP71A25 y CaCYP701A3 para la concentración de kahweol, por lo que, se han propuesto genes de este citocromo como potenciales candidatos para investigación de las etapas finales de los procesos de síntesis de estos lípidos (Ivamoto et al., 2017b).

Con respecto a oligosacáridos, se han identificado genes candidatos relacionados con síntesis de azúcares de la familia de la rafinosa como genes con actividad galactinol sintasa (CaGolS2, CaGolS3, CaGolS4, CaGolS8 y CaGolS9), rafinosa sintasa (CaRS1, CaRS5 y CaRS6) y estaquiosa sintasa (CaSTS) (Ivamoto et al., 2017a).

Se desarrolló un programa web denominado "CRIP" (Coffee gRNA Identification Program) (Breitler et al., 2018), que permite la identificación de todas las secuencias blanco de ARNg en el genoma de C. canephora, con la ventaja de identificar secuencias no blanco para cada secuencia guía. Dicho programa se probó escogiendo un gen extensamente usado en investigación de silenciamiento génico en plantas, como lo es el gen fitoeno desaturasa $C c P D S$, el cual produce un fenotipo albino fácilmente visible cuando es mutado. Inicialmente, se integró la herramienta al navegador que posee el genoma de café para luego seleccionar los ARNg para el gen específico en diferentes regiones (exón 3, 5 y 14), y por medio de transformación genética mediada por A. tumefaciens EHA105 se integraron las secuencias en callos embriogénicos de C. canephora L. Dichos explantes se llevaron hasta la etapa de plantas y con ellas se realizaron las extracciones de ADN genómico y luego PCR para fragmentos específicos en diferentes lugares del gen $C C P D S$ en todas las plantas, los productos de la amplificación se secuenciaron para posteriormente identificar las mutaciones. Además, por medio de RT-PCR, se corroboró la expresión del gen de la 
caspasa9. Se obtuvieron 94 plantas transformadas con el constructo con el ARNg dirigido hacia el exón 3, 56 para el exón 5 y 92 para el exón 14. De estas, se detectaron mutaciones en 30,4\% de las plantas transformadas con ARNg dirigidos para el exón 14, con un total de nueve diferentes mutaciones, mientras que para los otros exones no se obtuvieron mutantes. Ninguna de las plantas mostró un fenotipo albino completo, pero si un rango de fenotipos mutantes que incluían plantas con hojas pequeñas, lanceoladas, con pigmentación anormal (amarilla, clorótica), internudos más cortos y hojas faltantes o en algunos casos, en mayor número del normal. Así, se demostró que la edición de genomas por CRISPR-Cas9 es una manera eficiente y confiable de inactivar genes de interés agronómico.

La mayoría de los rasgos deseables de modificar tales como la calidad de taza, resistencia a plagas y/o patógenos o producción son de carácter poligénico, es decir, varios genes interactúan entre sí para dar como resultado la característica final, por lo que, al editar solamente un gen de todo el complejo es improbable que se logre la modificación del rasgo final. Sin embargo, esta técnica ha sido aplicada satisfactoriamente en otras especies, donde se ha logrado la edición de varios genes simultáneamente al introducir varios ARN guías, por lo que no se descarta que en un futuro y con más investigación pueda ser utilizada satisfactoriamente en este cultivo.

\section{Conclusión}

Hace más de treinta años que se comenzó a mejorar el café y los estudios y avances continúan actualmente por medio de tecnologías transgénicas y técnicas de modificación específica de genes como CRISPR-Cas9. Posiblemente, en un futuro cercano el cultivo y su producción se verán impactados de manera positiva gracias a todos estos esfuerzos e investigaciones.

\section{Literatura citada}

Acuña, J.R., and M. De-Peña. 1991. Plant regeneration from protoplasts of embryogenic cell suspensions of Coffea arabica L. cv. Caturra. Plant Cell Rep. 10:345-348. doi:10.1007/BF00193156

Agwanda, C.O. 1999. Twenty seven years of coffee breeding in Kenya: prospects for the release of new varieties. $18^{\text {th }}$ International Scientific Colloquium on Coffee. ASIC, FIN. https://www.asic-cafe.org/conference/18th-internationalscientific-colloquium-coffee/twenty-seven-years-coffee-breeding-kenya (accessed Mar. 13, 2006).

Agwanda, C., P. Lashermes, P. Trouslot, MC. Combes, and A. Charrier. 1997. Identification of RAPD markers for resistance to coffee berry disease, Colletotrichum kahawae, in arabica coffee. Euphytica 97:241-248. doi:10.1023/A:1003097913349

Albarrán, J.G. 1999. Influencia de los factores químicos y físicos sobre la regeneración de embriones somáticos de Coffea arabica en biorreactor simplificado. Tesis MSc., CATIE, Turrialba, CRI.

Albuquerque, E.V., W. Cunha, A. Barbosa, P. Costa, J. Teixeira, G. Vianna, G. Cabral, D. Fernandez, and M. Grossi. 2009. Transgenic coffee fruits from Coffea arabica genetically modified by bombardment. In Vitro Cell. Dev. Biol. Plant. 45:532-539 doi:10.1007/s11627-009-9254-2

Alemayehu, D. 2017. Review on genetic diversity of coffee (Coffea arabica L) in Ethiopia. Int. J. Forest. Hort. 3(2):18-27. doi:10.20431/2454-9487.0302003

Alpizar, E., E. Dechamp, B. Bertrand, P. Lashermes, and H. Etienne. 2007. Transgenic roots for functional genomics of coffee resistance genes to root-knot nematodes. In: Association for Science and Information on Coffee, editor, Proceedings of the $21^{\text {st }}$ International Conference on Coffee Science. Association for Science and Information on Coffee, Montpellier, FRA. p. 653-659. 
Alpizar, E., E. Dechamp, S. Espeout, M. Royer, A. Lecouls, M. Nicole, B. Bertrand, P. Lashermes, and H. Etienne. 2006. Efficient production of Agrobacterium rhizogenes-transformed roots and composite plants for studying gene expression in coffee roots. Plant Cell Rep. 25:959-967 doi:10.1007/s00299-006-0159-9

Alpizar, E., E. Dechamp, F. Lapeyre, C. Guilhaumon, B. Bertrand, C. Jourdan, P. Lashermes, and H. Etienne. 2008. Agrobacterium rhizogenes-transformed roots of coffee (Coffea arabica): Conditions for long-term proliferation, and morphological and molecular characterization. Ann. Bot. 101:929-940 doi:10.1093/aob/mcn027

AMC (Academia Mexicana de Ciencias). 2016. Edición genética con la técnica CRISPR/Cas9.55. AMC, MEX. http://www. coniunctus.amc.edu.mx/boletines/amc_boletin55.pdf (consultado 10 ene. 2018).

Arroyo, A., A. Ku, R. Canche, F. Quiroz, V. Loyola, L. Rodríguez, C. Burgeff, V. Súarez, and E. Castaño. 2008. Expression of WUSCHEL in Coffea canephora causes ectopic morphogenesis and increases somatic embryogenesis. Plant Cell Tiss. Organ Cult. 94:171-180 doi:10.1007/s11240-008-9401-1.

Azofeifa, A. 2006. Uso de marcadores moleculares en plantas; aplicaciones en frutales del trópico. Agron. Mesoam. 17:221-242. doi:10.15517/am.v17i2.5163

Barbón, R., E. Jiménez, A. Capote, V. Gil, y B. Ocaña. 2011. Transformación genética de Coffea arabica cv. Caturra rojo mediante la electroporación de suspensiones celulares embriogénicas. Biotecnol. Veg. 11(1):33-42.

Barbosa, A.E., E. Albuquerque, M. Silva, D. Souza, O. Oliveira, A. Valencia, T. Rocha, and M. Grossi. 2010. $\alpha$-Amylase inhibitor-1 gene from Phaseolus vulgaris expressed in Coffea arabica plants inhibits $\alpha$-amylases from the coffee berry borer pest. BMC Biotech. 10:44. doi:10.1186/1472-6750-10-44

Barros, E.V., G.B. Araujo, e A. Brasileiro. 2000. Transformação genética de Coffea arabica através de bombardeamento. SBICafé, BRA. http://www.sbicafe.ufv.br/handle/123456789/652 (acessado 10 Jan. 2018).

Barros, E.V., W.G Cunha, J.B. Teixeira, e A.C.M. Brasileiro. 2001. Expressão do gene Gus em embriões zigóticos e calos embriogênicos de Coffea arabica e C. canephora. Em: F. Mendes, e A. da-Silva, editores, Encontro do talento Estudantil da Embrapa Recursos Genéticos e Biotecnologia. Embrapa, Brasília, BRA. p. 36.

Barton, C., T. Adams, and M. Zarowitz. 1991. Stable transformation of foreign DNA into Coffea arabica plants. In: Association for Science and Information on Coffee, editor, Proceedings of the $14^{\text {th }}$ International Conference on Coffee Science. ASIC, San Francisco, CA, USA. p. 460-464.

Berthouly, M. 1997. Biotecnologías y técnicas de reproducción de materiales promisorios en Coffea arabica. En: E.L. Ibarra, editor, Memorias del XVII Simposio Latinoamericano de Caficultura. IICA-PROMECAFE, San José, CRI. p. 25-49.

Breitler, J.C., E. Dechambreitlerp, C. Campa, L. Zebral, R. Guyot, P. Marraccini, and H. Etienne. 2018. CRISPR/Cas9-mediated efficient targeted mutagenesis has the potential to accelerate the domestication of Coffea canephora. Plant Cell Tiss. Organ Cult. 134:383-394. doi:10.1007/s11240-018-1429-2

Canche, R.L., A. Ku, C. Burgeff, V. Loyola, L. Rodríguez, and E. Castaño. 2006. Genetic transformation of Coffea canephora by vacuum infiltration. Plant Cell Tiss. Organ Cult. 84:373-377. doi:10.1007/s11240-005-9036-4

Carneiro, M.F. 1993. Induction of double haploids on Coffea arabica cultivars via anther or isolated microscopes culture. In: Association for Science and Information on Coffee, editor, 15th International Scientific Colloquium on Coffee. ASIC, Montpellier, France. p. 133.

Cruz, A.R., A. Paixao, F. Machado, M. Barbosa, C. Junqueira, G. Cabral, J. Teixeira, A. Kobayashi, A. Brasileiro, e E. Barros. 2004. Metodologia para obtencao de plantas transformadas de Coffea canephora por co-cultivo de calos embriogenicos com Agrobacterium tumefaciens. Boletim de Pesquisa e Desenvolvimento. Embrapa, BRA. 
Cunha, W.G., e E. Barros. 2002. Transformação genética de calos embriogênicos de Coffea arabica via biobalística e seleção em canamicina. Embrapa, BRA. https://ainfo.cnptia.embrapa.br/digital/bitstream/CENARGEN/28564/1/tales2002.pdf (consultado 10 ene. 2018).

Cunha, W.G., F. Machado, G. Vianna, J. Teixeira, e V. Albuquerque. 2004. Obtenção de Coffea arabica geneticamente modificadas por bombardeamento de calos embriogênicos. Boletim de Pesquisa e desenvolvimento. Embrapa, BRA. https://ainfo.cnptia.embrapa.br/digital/bitstream/CENARGEN/28286/1/bp073.pdf (consultado 10 ene. 2018).

Davis, A., R. Govaerts., D. Bridson, and P. Stoffelen. 2006. An annotated taxonomic conspectus of the genus Coffea (Rubiaceae). Bot. J. Linn. Soc. 152:465-512. doi:10.1111/j.1095-8339.2006.00584.x

De-Block, M., LH. Estrella., M. Van-Montagu., J. Schell, and P. Zambryski. 1984. Expression of foreign genes in regenerated plants and in their progeny. EMBO J. 3:1681-1689. doi:10.1002/j.1460-2075.1984.tb02032.x

De-Gluglielmo, Z. 2009. Ingeniería genética aplicada al café. Rev. UDO Agric. 9:475-486.

De-Guglielmo, Z., I. Altosaar, M. Zaidi, and A. Menéndez. 2010a. Transformation of coffee (Coffea arabica L. cv. Catimor) with the crylac gene by biolistic, without the use of markers. Braz. J. Biol. 70:387-393.

De-Guglielmo, Z., R. Fernández, L. Hermoso, I. Altosaar, y A. Menéndez. 2010b. Optimización de los parámetros de transformación genética de café mediante biobalística con el gen reportero gus. Acta Biol. Venez. 30(1-2):23-34.

De-Kochko, A., S. Akaffou, A.C. Andrade, C. Campa, D. Crouzillat, R. Guyot, P. Hamon, R. Ming, LA. Mueller, V. Poncet, C. Tranchant, and S. Hamon. 2010. Advances in Coffea genomics. Adv. Bot. Res. 53:23-63. doi:10.1016/s000652296(10)53002-7

Denoeud, F., L. Carretero, A. Dereeper, G. Droc, R. Guyot, M. Pietrella, C. Zheng, A. Alberti, F. Anthony, G. Aprea, J. Aury, P. Bento, M. Bernard, S. Bocs, C. Campa, A. Cenci, M. Combes, D. Crouzillat, C. Da-Silva, L. Daddiego, F. De Bellis, S. Dussert, O. Garsmeur, T. Gayraud, V. Guignon, K. Jahn, V. Jamilloux, T. Joet, K. Labadie, T. Lan, J. Leclercq, M. Lepelley, T. Leroy, L. Li, P. Librado, L. Lopez, A. Muñoz, B. Noel, A. Pallavicini, G. Perrotta, V. Poncet, D. Pot, M. Rigoreau, M. Rouard, J. Rozas, C. Tranchant, R. Van-Buren, Q. Zhang, A. Andrade, X. Argout, B. Bertrand, A. De Kochko, G. Graziosi, R. Henry, R. Ming, C. Nagai, S. Rounsley, D. Sankoff, G. Giuliano, V. Albert, P. Wincker, and P. Lashermes. 2014. The coffee genome provides insight into the convergent evolution of caffeine biosynthesis. Science 345:1181-1184. doi:10.1126/science.1255274

Díaz, C., y A. Chaparro. 2012. Métodos de transformación genética de plantas. Rev. U.D.C.A Actual. Divulg. Cient. 15(1):4961.

Dufour, M., T. Leroy, C. Carasco, R. Philippe, and C. Fenouillet. 2000. Coffee (Coffea sp.) genetic transformation for insect resistance. In: T. Sera et al., editors, Coffee biotechnology and quality. Springer, Dordrecht, NLD. p. 209-217. doi:10.1007/978-94-017-1068-8_18

Espejo, R., G. Cipriani, G. Rosel, A. Golmirzaie, and W. Roca. 2008. Somatic hybrids obtained by protoplast fusion between Solanum tuberosum L. subsp. tuberosum and the wild species Solanum circaeifolium Bitter. Rev. Peru. Biol. 15:73-78. doi:10.15381/rpb.v15i1.1678

Fernández, R., Z. De-Guglielmo, and A. Menéndez. 2010. Cultivo de tejidos y transformación genética de café. Rev. Invest. 34(71):57-84.

Fernandez, R., and A. Menéndez. 2003. Transient gene expression in secondary somatic embryos from coffee tissues electroporated with the genes gus and bar. Electron. J. Biotechnol. 6:29-35. doi:10.2225/vol6-issue1-fulltext-6 
Gatica, A.M., G. Arrieta, and A. Espinoza. 2008. Plant regeneration via indirec somatic embryogenesis and optimisation of genetic transformation in Coffea arabica L. cvs Caturra and Catuaí. Electron. J. Biotechnol. 11:1-11. doi:10.2225/vol11issue 1-fulltext-9

Gatica, A.M., G. Arrieta, and A. Espinoza. 2009. Optimization of coffee (Coffea arabica) transformation parameters using uidA and hpt genes: effect of osmotic pre-treatment, helium pressure and target distance. Rev. Biol. Trop. 57:151-160.

Gichuru, E., C.O. Agwanda, M.C. Combes, E.W. Mutitu, E.C. Ngugi, B. Bertrand, and P. Lashermes. 2008. Identification of molecular markers linked to a gene conferring resistance to coffee berry disease (Colletotrichum kahawae) in Coffea arabica. Plant Pathol. 57:1117-1124. doi:10.1111/j.1365-3059.2008.01846.x

Giménez, C.A., A. Menéndez, y E. De-García. 1996. Efecto del antibiótico kanamicina sobre diferentes explantes del híbrido de café (Coffea sp.) Catimor. Phyton 59:39-46.

Grézes, J., B. Thomasset, and D. Thomas. 1994. Factors influencing protoplasts isolation from Coffea arabica cells. Plant Cell Tiss. Organ Cult. 36:91-97. doi:10.1007/BF00048319

Gutiérrez, A., F. Santacruz, J. Cabrera, y B. Rodríguez. 2003. Mejoramiento genético vegetal in vitro.e-Gnosis 1:4. doi:10.1007/ BF00048319

Hatanaka, T., Y. Choi, T. Kusano, and H. Sano. 1999. Transgenic plants of coffee Coffea canephora from embryogenic callus via Agrobacterium tumefaciens-mediated transformation. Plant Cell Rep. 19:106-110. doi:10.1007/s002990050719

Hendre, P, and R.K. Aggarwal. 2007. DNA markers: Development and application for genetic improvement of coffee. In: R.K. Varshney, and R. Tuberosa, editors, Foreword to the series: Genomics-assisted crop improvement. Genomics Applications in Crops. Springer, Dordrecht, NLD. p. 399-434. doi:10.1007/978-1-4020-6297-1_15

ICAFE (Instituto Del Café de Costa Rica). 2016. Informe sobre la actividad cafetalera de Costa Rica. ICAFE, Heredia, CRI. http://www.icafe.cr/wp-content/uploads/informacion_mercado/informes_actividad/anteriores/2016.pdf (consultado 10 ene. 2018).

Ivamoto, S.T., O. Reis, D. Silva, T. Benedito, F. Freitas, D. Pot, T. Leroy, L. Gonzaga, M. Falsarella, G. Amarante, and L. Protasio. 2017a. Transcriptome analysis of leaves, flowers and fruits perisperm of Coffea arabica L. reveals the differential expression of genes involved in raffinose biosynthesis. PLoS One 12(1):e0169595. doi:10.1371/journal.pone.0169595

Ivamoto, S.T., L. Sakuray, L. Ferreira, C. Kitzberger, M. Scholz, D. Pot, T. Leroy, L. Vieira, D. Domingues, and L. Pereira. 2017b. Diterpenes biochemical profile and transcriptional analysis of cytochrome P450s genes in leaves, roots, flowers, and during Coffea arabica L. fruit development. Plant Physiol. Biochem. 111:340-347. doi:10.1016/j.plaphy.2016.12.004

Kumar, V., K. Satyanarayana, A. Ramakrishna, A. Chandrashekar, and G. Ravishankar. 2007. Evidence for localization of $\mathrm{N}$-methyltransferase (NMT) of caffeine biosynthetic pathway in vacuolar surface of Coffea canephora endosperm elucidated through localization of GUS reporter gene driven by NMT promoter. Curr. Sci. 93:383-386.

Kumar, V., K. Satyanarayana, S. Sarala, E. Indu, P. Giridhar, A. Chandrashekar, and G. Ravishankar. 2006. Stable transformation and direct regeneration in Coffea canephora P ex. Fr. by Agrobacterium rhizogenes mediated transformation without hairy-root phenotype. Plant Cell Rep. 25:214-222 doi:10.1007/s00299-005-0045-x

Kumar, V., V. Sathyanarayana, S. Saarala, P. Giridhar, A. Chandrasekhar, and G. Ravishankar. 2004. Post transcriptional gene silencing for down regulating caffeine biosynthesis in Coffea canephora P. ex Fr. In: Association for Science and Information on Coffee, editor, Proceedings of the 20th International Conference on Coffee Science. ASIC, Bangalore, IND. p. 769-774.

Labouisse, J.P., B. Bellachew, S. Kotecha, and B. Bertrand. 2008. Current status of coffee (Coffea arabica L.) genetic resources in Ethiopia: implications for conservarion. Genet. Resour. Crop Evol. 55:1079-1093. doi:10.1007/s10722-008-9361-7 
Lammoglia, M.F., R. Lozano, C. García, C. Avilez, V. Trejo, R. Muñoz, and C. López. 2016. The revolution in genetic engineering: CRISPR/Cas system. Invest. Discap. 5(2):116-128.

Lashermes, P., A. Carvalho, and H. Etienne. 2008. Genomics of coffee, one of the world's largest traded commodities. In: P.H. Moore, and R. Ming, editors, Genomics of tropical crop plants. Vol. 1. Plants genetics and genomics: Crops and models. Springer, NY, USA. p. 203-226. doi:10.1007/978-0-387-71219-2_9

Lashermes, P., MC. Combes, J. Robert, P. Trouslot, AD. Hont, F. Anthony, and A. Charrier. 1999. Molecular characterization and origin of the Coffea arabica L. genome. Mol. Gen. Genet. 261:259-266. doi:10.1007/s004380050

Lashermes, P., MC. Combes, P. Topart, G. Graziosi, B. Bertrand, and F. Anthony. 2000. Molecular breeding in coffee (Coffea arabica L.). In: T. Sera et al., editors, Coffee biotechnology and quality. Springer, Dondrecht, NLD. p. 101-112. doi:10.1007/978-94-017-1068-8_7

Leroy, T., A. Henry, M. Royer, I. Altosaar, R. Frutos, D. Duris, and R. Philippe. 2000. Genetically modified coffee plants expressing the Bacillus thuringiensis cry1Ac gene for resistance to leaf miner. Plant Cell Rep. 19:382-389. doi:10.1007/ s002990050744

Leroy, T., M. Royer, et M. Paillard. 1997. Introduction de gènes d'intérêt agronomique dans l'espèce Coffea canephora Pierre par transformation avec. Agrobacterium sp. Fr: Association for Science and Information on Coffee, editor, Dix-septième colloque scientifique international sur le café. ASIC, Paris, FRA. p. 439-446.

Liu, X., S. Wu, J. Xu, C. Sui, and J. Wei. 2017. Application of CRISPR/Cas9 in plant biology. APSB 7:292-302. doi:10.1016/j. apsb.2017.01.002

Llop, P. 2003. Caracterización molecular de la pérdida del poder patógeno en Agrobacterium tumefaciens. Tesis Dr., Universitat De Valencia Servei de Publicacions, Valencia, ESP.

López, K., D. Rodríguez, y J. Vaca. 2013. Optimización de las condiciones de inoculación por biobalística de un Begomovirus en tomate y tabaco. Rev. Colomb. Biotecnol. 15(2):8-17. doi:10.15446/rev.colomb.biote.v15n2.41261

McCown, B.H., and G. Lloyd. 1981. Woody plant medium (WPM)-A mineral nutrient formulation for microculture of woody plant species. HortSci. 16:453-453.

Melese, K. 2016. The role of biotechnology on coffee plant propagation: A current topics paper. J. Biol. Agric. Healthcare 6(5):13-19

Mishra, M.K., S. Devi, A. McCormac, N. Scott, D. Chen, M. Elliott, and A. Slater. 2010. Green fluorescent protein as a visual selection marker for coffee transformation. Biologia 65:639-646 doi:10.2478/s11756-010-0078-7

Mishra, M.K., and A. Slater. 2012. Recent advances in the genetic transformation of coffee. Biotechnol. Res. Int. 2012:580857. doi:10.1155/2012/580857

Mishra, M.K., and H. Sreenath. 2004. High-efficiency Agrobacterium-Mediated transformation of coffee (Coffea canephora Pierre ex. Frohner) using hypocotyl explants. In: Association for Science and Information on Coffee, editor, Proceedings of the $2^{\text {tth }}$ International Conference on Coffee Science. ASIC, Bangalore, IND. p. 792-796.

Mishra, M.K., H. Sreenath, A. Jayarama, A. McCormac, S. Devi, M. Elliott, and A. Slater. 2008. Two critical factors: Agrobacterium strain and antibiotics selection regime improve the production of transgenic coffee plants. In: Association for Science and Information on Coffee, editor, Proceedings of the $22^{\text {th }}$ International Association for Coffe Science. ASIC, Campinas, BRA. p. 843-850.

Mishra, M.K., H. Sreenath, and C. Srinivasan. 2002. Agrobacterium-mediated transformation of coffee: an assessment of factors affecting gene transfer efficiency. In: Association for Science and Information on Coffee, editor, Proceedings of the $15^{\text {th }}$ Plantation Crops Symposium Placrosym XV. ASIC, Mysore, IND. p. 251-255. 
Montero, W., y V. Jimenéz. 2009. Identificación y selección de híbridos somáticos obtenidos mediante fusión de protoplastos. Biotecnol. Veg. 9(2):67-90.

Morillo, S.X. 2011. Evaluación del control de Agrobacterium tumefaciens mediante la aplicación de agentes antibióticos en rosas. Informe Ing. Agropecu., Universidad de Fuerzas Armadas ESPE, Sangolquí, ECU.

Nester, E.W. 2015. Agrobacterium: nature's genetic engineer. Front. Plant Sci. 5:730. doi:10.3389/fpls.2014.00730

Ocampo, C.A., and L. Manzanera. 1991. Advances in genetic manipulation of coffee plant. In: Association for Science and Information on Coffee, editor, Proceedings of $14^{\text {th }}$ Colloquium of International Coffee Science Association. ASIC, San Francisco, CA, USA. p. 378-382.

Ogita, S., H. Uefuji, M. Morimoto, and H. Sano. 2004. Application of RNAi to confirm theobromine as the major intermediate for caffeine biosynthesis in coffee plants with potential for construction of decaffeinated varieties. Plant Mol. Biol. 54:931-941. doi:10.1007/s11103-004-0393-x

Orozco, F.J., y D. Schieder. 1982. Aislamiento y cultivo de protoplastos a partir de hojas de café. Cenicafé 33(4):129-136.

Pensabene, G. 2009. Aplicación de la hibridación somática a la mejora de la citrucultura española. Tesis Dr., Universidad Politécnica de Valencia. Valencia, ESP.

Perthuis, B., J. Pradon, C. Montagnon, M. Dufour, and T. Leroy. 2005. Stable resistance against the leaf miner Leucoptera coffeella expressed by genetically transformed Coffea canephora in a pluriannual field experiment in French Guiana. Euphytica 144:321-329. doi:10.1007/s10681-005-8003-9

Ran, F.A., P. Hsu, J. Wright, V. Agarwala, D. Scott, and F. Zhang. 2013. Genome engineering using the CRISPR-Cas9 system. Nat. Protoc. 8:2281-2308. doi:10.1038/nprot.2013.143

Ribas, A.F., E. Dechamp, A. Champion, B. Bertrand, M. Combes, J. Verdeil, F. Lapeyre, P. Lashermes, and H. Etienne. 2011. Agrobacterium-mediated genetic transformation of Coffea arabica (L.) is greatly enhanced by using established embryogenic callus cultures. BMC Plant Biol. 11:92. doi:10.1186/1471-2229-11-92

Ribas, A.F., R.M. Galvão, L.F.P. Pereira, e L.G.E. Vieira. 2006a. Transformação de Coffea arabica com o gene da ACC-oxidase em orientação antisenso. Em: Association for Science and Information on Coffee, editor, Proceedings of the $50^{\text {th }}$ Congreso Brasileiro de Genética. ASIC, São Paulo, BRA. p. 492-493.

Ribas, A.F., A. Kenji, L. Protasio, and L. Esteves. 2006b. Production of herbicide-resistant coffee plants (Coffea canephora P.) via Agrobacterium tumefaciens-mediated transformation. Braz. Arch. Biol. Technol. 49:11-19. doi:10.1590/S151689132006000100002

Ribas, A.F., A. Kobayashi, L. Pereira, and L. Vieira. 2005. Genetic transformation of Coffea canephora by particle bombardment. Biol. Plantarum 49:493-497. doi:10.1007/s10535-005-0038-1

Ribas, A.F., L. Protasio, L. Gonzaga, and E. Vieira. 2006c. Genetic transformation of coffee. Plant Physiol. 18:83-94. doi:10.1590/S1677-04202006000100007

Rosillo, A.G., J. Acuna, A. Gaitan, and M. De-Pena. 2003. Optimised DNA delivery into Coffea arabica suspension culture cells by particle bombardment. Plant Cell Tiss. Organ Cult. 74:45-49. doi:10.1023/A:1023314128543

Sander, J.D., and K. Joung. 2014. CRISPR-CAS systems for editing, regulating and targeting genomes. Nat. Biotechnol. 32:347355. doi:10.1038/nbt.2842

Sant'Ana, G.C., L. Pereira, D. Pot, S. Ivamoto, D. Domingues, R. Ferreira, N. Pagiatto, B. Da Silva, L. Nogueira, C. Kitzberger, M. Scholz, F. De-Oliveira, G. Sera, L. Padilha, J. Laboiusse, R. Guyot, P. Charmetant, and T. Leroy. 2018. Genome-wide association study reveals candidate genes influencing lipids and diterpenes contents in Coffea arabica L. Sci. Rep. 8:465. doi:10.1038/s41598-017-18800-1 
Schopke, C., L. Muller, and H. Kohlenbach. 1987. Somatic embryogenesis and regeneration of plantlets in protoplast cultures from somatic embryos of coffee (Coffea canephora P. exFr). Plant Cell Tiss. Organ Cult. 8:243-248. doi:10.1007/ BF00040951

Solano, W. 2001. Efecto de las características de cultivo en suspensión celular y en biorreactor con inmersión temporal sobre la propagación masiva de Coffea arabica por embriogénesis somática. Tesis Lic., Universidad de Costa Rica, Turrialba, CRI.

Sondahl, M.R., M. Champman, and N. Sharp. 1980. Protoplast liberation, cell wall construction and callus proliferation in Coffea arabica $\mathrm{L}$. callus tissues. Turrialba 30:161-165.

Souto, L., F. De-Araújo, N. Gomes, K. Duarte, R. Oliveira, J.C. Alekcevetch, M. Guitton, J.L. Verdeil, F. Lapeyre-Montes, M. Lartaud, T. Leroy, F. De-Bellis, D. Pot, G. Costa, M. Falsarella, G. Guimarães, A. Carvalho, and P. Marraccini. 2016. Identification of candidate genes for drought tolerance in coffee by high-throughput sequencing in the shoot apex of different Coffea arabica cultivars. BMC Plant Biol. 16:94. doi:10.1186/s12870-016-0777-5

Spiral, J., and V. Petiard. 1991. Protoplast culture and regeneration in coffee species. In: Association for Science and Information on Coffee, editor, Proceedings of the $14^{\text {th }}$ International Conference on Coffee Science. ASIC, San Francisco, CA, USA. p. 383-391.

Spiral, J., C. Thierry, M. Paillard, et V. Petiard. 1993. Obtention de plantules de Coffea canephora Pierre (Robusta) transformées par Agrobacterium rhizogenes. Compt. Rend. l'Academ. Sci. Paris 316(1):1-6.

Sridevi, V., P. Giridhar, P. Simmi, and G. Ravishankar. 2010. Direct shoot organogenesis on hypocotyl explants with collar region from in vitro seedlings of Coffea canephora Pierre ex. Frohner cv. C X R and Agrobacterium tumefaciens-mediated transformation. Plant Cell Tiss. Organ Cult. 101:339-347 doi:10.1007/s11240-010-9694-8

Stein, V.C. 2009. Biotechnological approaches to improve drought tolerance of Coffea arabica. Tesis Dr., Universidade Federal de Lavras, Minas Gerais, BRA.

Sugiyama, M., C. Matsuoka, and T. Takagi. 1995. Transformation of coffea with Agrobacterium rhizogenes. In: Association for Science and Information on Coffee, editor, Proceedings of the $16^{\text {th }}$ International Conference on Coffee Science. ASIC, Kyoto, JPN. p. 853-859.

Tran, H.T., L. Slade, A. Furtado, H. Smyth, and R. Henry. 2016. Advances in genomics for the improvement of quality in coffee. J. Sci. Food Agric. 96:3300-3312. doi:10.1002/jsfa.7692

Valderrama, A.M., R. Arango, y L. Afanador. 2005. Transformación de plantas mediada por Agrobacterium: "Ingeniería Genética Natural Aplicada”. Rev. Fac. Nal. Agr. 58:2569-2585.

Van-Boxtel, J.V. 1994. Studies on genetic transformation of coffee by using electroporation and the biolistic method. PhD. Diss., Univesity of Wageningen, NLD.

Van-Boxtel, J.V., M. Berthouly, C. Carasco, M. Dufour, and A. Eskes. 1995. Transient expression of $\beta$-glucuronidase following biolistic delivery of foreign DNA into coffee tissues. Plant Cell Rep. 14:748-752. doi:10.1007/BF00232915

Van-Der-Vossen, H., B. Bertrand, and A. Charrier. 2015. Next generation variety development for sustainable production of arabica coffee (Coffea arabica L.): a review. Euphytica 204:243-256. doi:10.1007/s10681-015-1398-Z

Zhong,G.Y.2001. Genetic issues and pitfalls in transgenic plant breeding. Euphytica 118:137-144.doi:10.1023/A:1004048019670

Agron. Mesoam. 30(2):577-599, mayo-agosto, 2019 